\title{
The seasonal circulation and volume transport on the northwest European continental shelf: A fine-resolution model study
}

\author{
Jason Holt ${ }^{1}$ and Roger Proctor ${ }^{1}$ \\ Received 28 November 2006; revised 13 September 2007; accepted 22 January 2008; published 24 June 2008.
}

[1] In this paper the circulation of the northwest European continental shelf is investigated using the first year-long density-evolving simulation at shelf wide scales and sub-Rossby Radius resolution $(\sim 1.8 \mathrm{~km})$. A series of numerical experiments are conducted to distinguish between the wind-, density-, and oceanic-driven components of the flow. These demonstrate that, while all components have a role throughout the year, the density-driven component is particularly important during the summer and autumn months. The time evolution of the density field makes a significant contribution to the seasonal variation of volume transport on shelf wide scales and is persistent in direction; whereas the wind-driven volume transport acts on much shorter timescales and is more variable in direction. The importance of the oceanic forcing is demonstrated, representing tidal residuals and large-scale oceanic sea level (pressure) variation; this forcing drives a substantial component of the circulation throughout the year. Twenty six satellite tracked drifters deployed in the summer of 2001 are used for a direct validation of the model currents. The model current speeds are found to be accurate to $\sim 46 \%$ when averaged over $\sim 40 \mathrm{~d}$, but tend to be too slow. The summer volume fluxes are compared with estimates in the literature showing good agreement, although there is a suggestion that the North Sea inflows are overestimated. Comparisons with the coarser resolution model used for boundary conditions demonstrate the importance of fine-resolution to the details of the frontal currents with consequences for modeling exchange processes and biological activity in these regions.

Citation: Holt, J., and R. Proctor (2008), The seasonal circulation and volume transport on the northwest European continental shelf: A fine-resolution model study, J. Geophys. Res., 113, C06021, doi:10.1029/2006JC004034.

\section{Introduction}

[2] The circulation of the northwest European continental shelf (Figure 1) has been the subject of intense investigation, because of its importance to the major northern European fisheries; a canonical schematic of the circulation in the North Sea derived from a variety of observations is presented in Figure 2 (reproduced from OSPAR [2000], after Turrell et al. [1992]). The earliest studies focused on the tide and wind-driven circulation, but it has long been known that, just as in the deep ocean, horizontal density gradients play a significant role. The subtidal circulation of shelf seas is composed of a combination of tidal residuals, wind (and atmospheric pressure)-driven currents, and density-driven currents. These forcing mechanisms all have local and nonlocal manifestations; the imposed stresses and pressure gradients are local effects, while the propagation of coastally trapped waves is the nonlocal (free) response to this forcing. In the context of regional scale modeling, the

\footnotetext{
${ }^{1}$ Proudman Oceanographic Laboratory, Liverpool, UK.
}

Published in 2008 by the American Geophysical Union. oceanic boundary conditions imposed on a model can form a significant part of the nonlocal forcing. The objective of this work is to identify the relative importance of the wind-, density-, and oceanic-driven circulation to the shelf-wide space- and seasonal time-scale transport across the northwest European continental shelf. For this purpose, a high resolution application of the Proudman Oceanographic Laboratory Coastal Ocean Modeling System [POLCOMS; Holt and James, 2001] is employed.

[3] Since the pioneering work of Heaps and Jones [1969] and Simpson and Hunter [1974], there has been increasing investigation of the density-driven circulation in these shelf seas particularly with the development of satellite-tracked drifters, undulating Conductivity Temperature Depth sensors (CTDs), accurate Acoustic Doppler Current Profilers (ADCPs) and, more recently, gliders. These observational techniques have been used to identify, on a case by case basis, a series of intense subsurface jets around the frontal regions of the northwest European shelf, these generally occur just above the bottom front where the thermocline curves down to the seabed. Examples of these jets include: the cyclonic gyre in the western Irish Sea [Hill et al., 1994]; the frontal jets in the St. George's Channel [Brown et al., 2003; Horsburgh et al., 1998], western English Channel (see http://www.cefas.co.uk/Publications/files/AE1225 

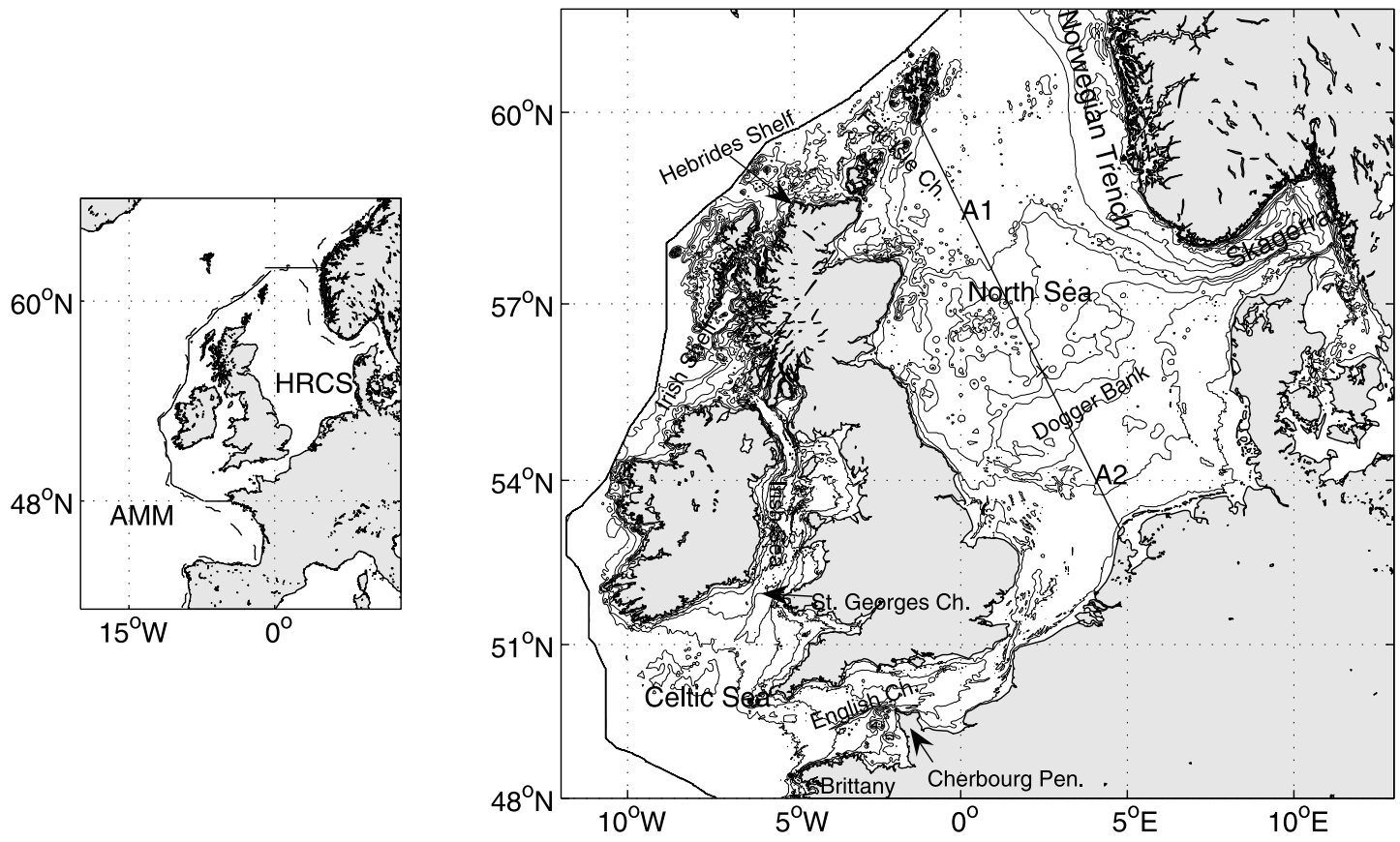

Figure 1. Model domains showing the nesting (left) of the High Resolution Continental Shelf model (HRCS) within the Atlantic Margin Model (AMM); the dashed line shows the $200 \mathrm{~m}$ isobath. The panel on the right shows the model bathymetry (prepared for the Northwest European shelf Operational Oceanographic System (NOOS); contour interval is $20 \mathrm{~m}$ up to $100 \mathrm{~m}$ and thereafter $100 \mathrm{~m}$ ), and the location of section A used in Figures 5 and 7-10 (A1 and A2).
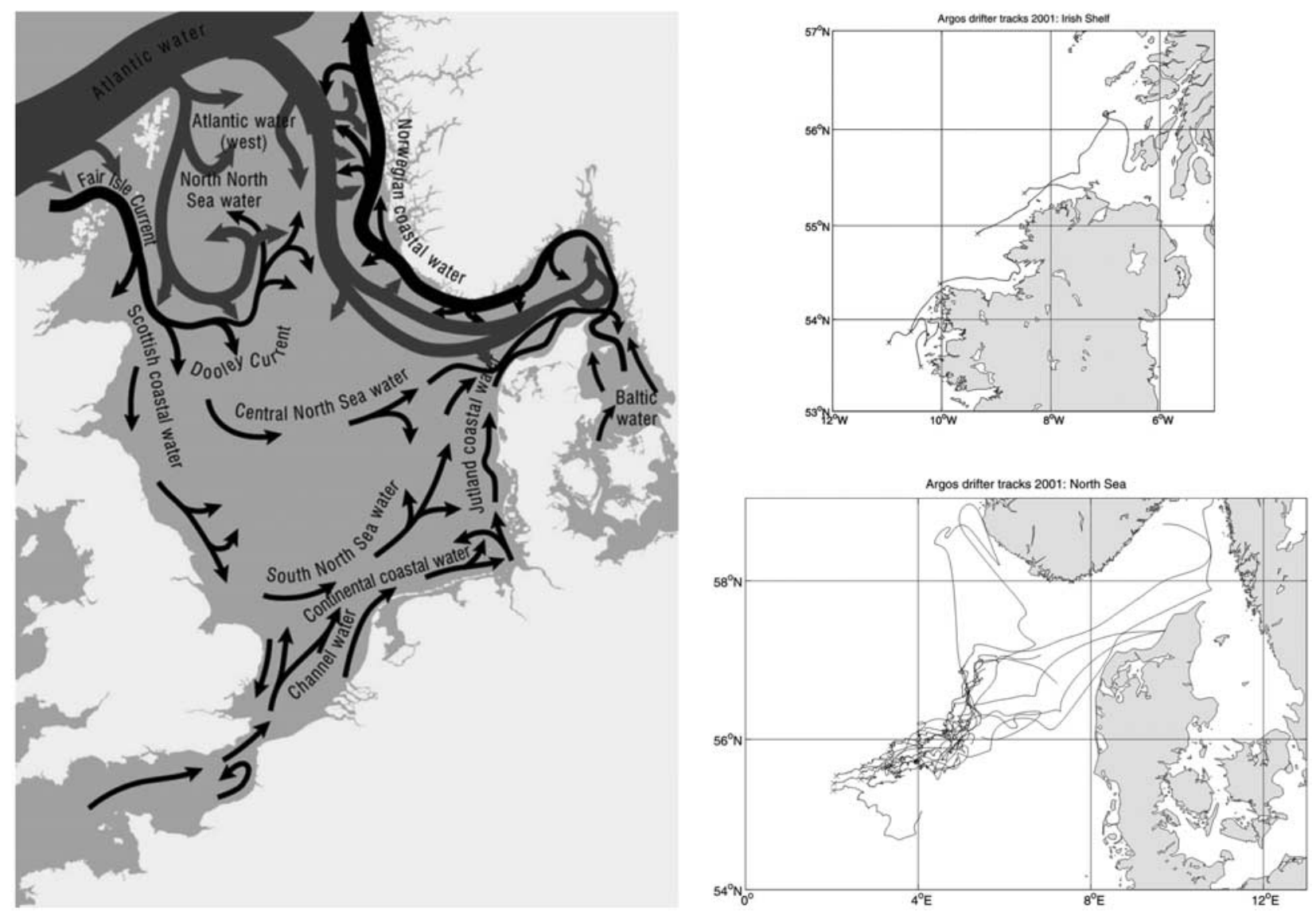

Figure 2. The canonical circulation pattern on the northwest European shelf (left), (reproduced from OSPAR [2000]) and Argos tracked drifters from summer 2001 (right). 


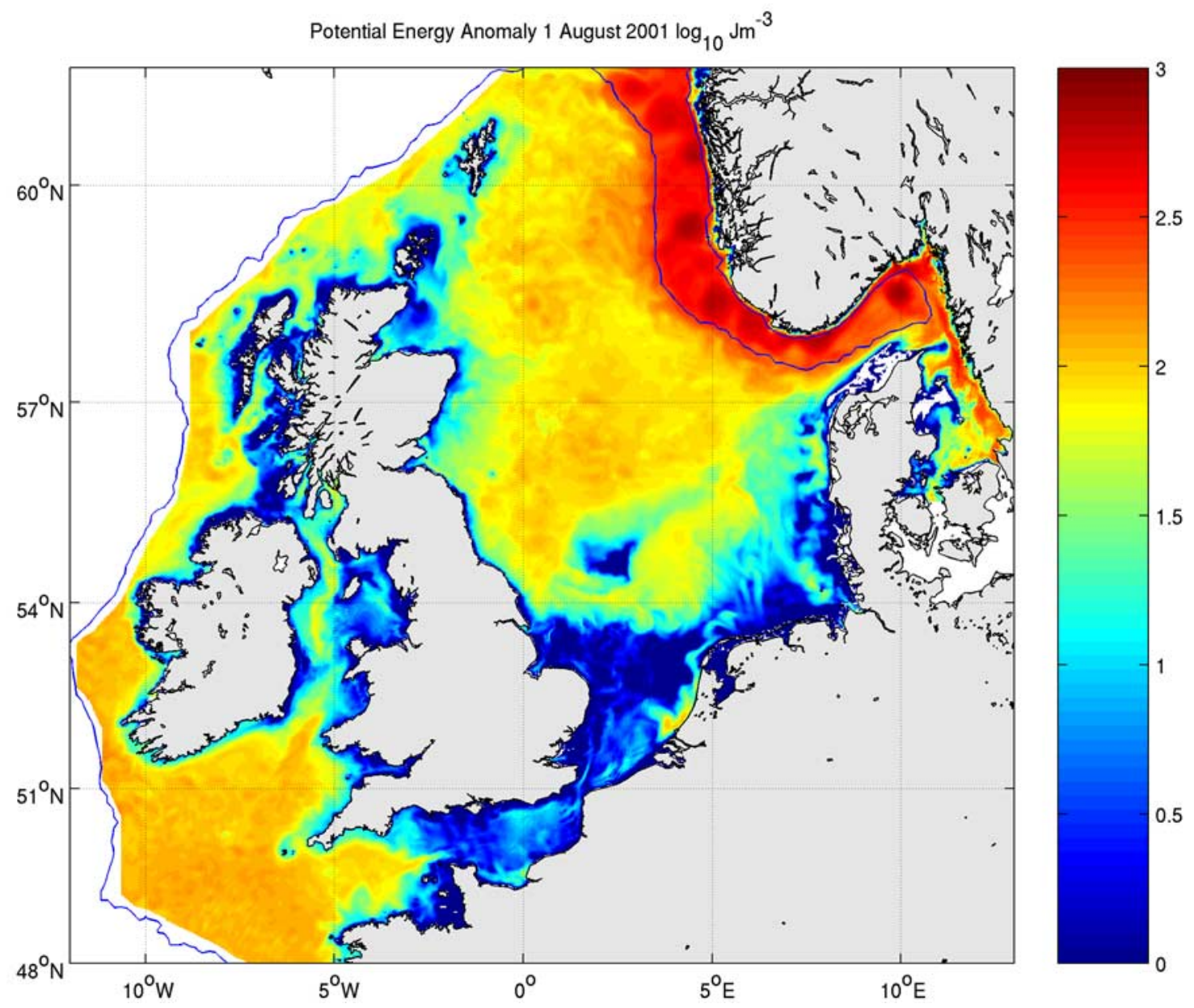

Figure 3. Potential energy anomaly (log scale) from this model simulation (1 August 2001).

leaflet_final.pdf), and in the region of Dogger Bank in the North Sea [Brown et al., 1999]; and the Irish coastal current [Fernand et al., 2006]. While these smaller (transverse) scale ( $\sim 10$ to $20 \mathrm{~km})$ features have been intensively studied, the relative role of density- and wind-driven currents on large space/timescales has yet to be established.

[4] The characteristic scale of the density structure is the internal Rossby radius, $L_{R}=\left[g^{\prime} h_{1} h_{2} /\left(h_{1}+h_{2}\right)\right]^{1 / 2} / f$ for a twolayer system with reduced gravity $g^{\prime}$ and layer depths $h=$ $h_{1}+h_{2}$; typically $2-5 \mathrm{~km}$ on the shelf and $\sim 14 \mathrm{~km}$ in the Norwegian Trench. The actual transverse scale of density driven currents also depends on the diffusive spreading of the density structure beyond the initial width of adjustment. The scale of coastal currents driven by freshwater sources is determined by a combination of bottom topography, input flux, and vertical and horizontal diffusion [Chapman, 2000; Chapman and Lentz, 1994; Narayanan and Garvine, 2002]. The largest such current in this region is the Norwegian Coastal Current $(\sim 85 \mathrm{~km}$ wide off the southern coast of Norway), an intense poleward current along the Norwegian coast carrying North Sea water recirculated in the Skaggerak and fresher water from the Baltic.

[5] The subsurface jets at tidal mixing fronts arise from the tendency for friction to retard the bottom component of the baroclinic flow associated with the frontal density structure, resulting in a subsurface cyclonic circulation above the bottom front; i.e., with mixed water to the right of the current [Garrett and Loder, 1981; Hill, 1996]. The horizontal width of these flows (typically $10-20 \mathrm{~km}$ ) is determined by the frontal density structure, which in turn depends on a range of cross-frontal exchange processes. Based on these scales, the model resolution for this study is chosen to be $\sim 1.8 \mathrm{~km}$. Hence on the shelf, this model is "eddy-permitting" rather than "eddy-resolving" in the sense that motions at the Rossby radius are included but not well resolved. An eddy-resolving model would require a resolution of finer than $200 \mathrm{~m}$ and would draw into question the hydrostatic approximation applied in this model.

[6] The frontal positions on the shelf can be defined by the horizontal gradients of the potential energy anomaly (Figure 3). This represents the energy required to completely mix the water column and is given by:

$$
\phi=-\frac{g}{h} \int_{z=-h}^{0} z(\rho(T, S)-\rho(\bar{T}, \bar{S})) d z,
$$

where $\rho$ is the density and an over-bar indicates a depth mean [Simpson and Bowers, 1981]. The frontal positions closely match those frontal positions presented by Pingree and Griffiths [1977] from the application of Simpson and Hunter's [1974] " $h / u^{3}$ " criteria to a depth averaged tidal model, which in turn shows good agreement with climatological observations [Bowers and Simpson, 1987]. 
The horizontal gradients in potential energy anomaly also give an indication of the strength of the density-driven circulation, so from the frontal positions on Figure 3 it can be inferred that subsurface jets have a role in transporting material in each of the seas covered by this model domain.

[7] Model studies are ideal for investigating the composition of the circulation, since the wind/tide/density contributions cannot generally be established unambiguously from observations. Moreover, observations cannot provide a synoptic view on a shelf-wide scale. A number of baroclinic modeling systems have been used to investigate the circulation of this region. These typically have resolutions of $7-20 \mathrm{~km}$, and are run for both operational and research purposes. Examples include the Hybrid Coordinate Ocean Model (HYCOM), $7 \mathrm{~km}$ [Winther and Evensen, 2006], the Hamburg Shelf Ocean Model (HAMSOM) at $\sim 20 \mathrm{~km}$ resolution [Backhaus and Hainbucher, 1987], the Princeton Ocean Model (POM) at $\sim 20 \mathrm{~km}$ [Skogen and Soiland, 1998] and POLCOMS at $7 \mathrm{~km}$ [Holt et al., 2005; Siddorn et al., 2007]. These modeling studies generally agree with the expected circulation pattern on the northwest European shelf derived from observational studies: throughout the region the currents tend to follow the direction of (barotropic and baroclinic) Kelvin wave propagation. This flow orientation is true for the tidal, wind-driven and coastal-current circulations (with the coast to the right of the current), and frontal jets with well-mixed waters to the right of the current. Since well-mixed water tends to be shoreward of the frontal jet, all mechanisms drive currents in the same direction, a possible source of ambiguity when attempting to identify the forcing mechanism. This flow orientation is not the case for isolated banks (such as Dogger Bank) and fronts there can drive currents in the opposite direction to the large scale circulation [e.g., Brown et al., 1999]. While the general patterns have been reproduced, direct comparisons between model currents and contemporary observations are rare and have not yet been carried out on a shelf-wide scale.

[8] To date there are no published model studies of the density-driven circulation across the whole of the northwest European shelf region shown in Figure 1 that includes motions at the scale of the internal Rossby radius; i.e., are eddy-permitting. In this work a fine-resolution shelf-wide application of POLCOMS is employed in a study of an annual cycle. Unlike in previous model studies of this region the resolution considered here is fine enough to resolve the details of the density-driven frontal circulation, while the scale is large enough to include all the frontal systems on the shelf and also the large-scale circulation. In the geostrophic limit the net volume flux across a section is only dependent on the pressure difference between the beginning and end of the section; hence resolution is not necessarily important in determining the large scale transport, as long as the sea level and density structure are well represented. However, the detailed structure of the currents in frontal jets is strongly resolution dependent, and the bottom topography and friction both tend to make this structure important to the larger scale volume transport. One of the objectives of this paper is to identify the importance of these effects, which have been detailed locally by a range of observational studies [e.g., Brown et al., 2003; Hill et al., 1994; Lwiza et al., 1991].
[9] To validate this model simulation satellite tracked drifter observations (Figure 2) are used to provide a direct comparison in the central North Sea and Irish Shelf regions. A semiqualitative comparison with volume transport estimates in the literature is made to assess the fluxes across the whole model domain.

[10] The model experiments are described in the next section and the shelf-wide circulation pattern is described in section 3. Volume transport across a number of sections is investigated in section 4 and conclusions drawn in section 5.

\section{Model Description, Experiments and Diagnostics}

[11] We use the POLCOMS to simulate the region shown in Figure 1 on a $1 / 60^{\circ}$ latitude by $1 / 40^{\circ}$ longitude grid $(\sim 1.8 \mathrm{~km})$, with 34 vertical s-coordinate levels [Song and Haidvogel, 1994]. This configuration is known as the High Resolution Continental Shelf (HRCS) model. POLCOMS is a B-grid finite difference model with prognostic temperature and salinity, and a sophisticated advection scheme [the "Piecewise Parabolic Method"; James, 1996]. The model is fully described by Holt and James [2001], so these details will not be repeated here. The model is forced by 6-hourly European Centre for Medium Range Weather Forecasting (ECMWF) atmospheric model data, using bulk formulae [Gill, 1982; Smith and Banke, 1975] to prescribe surface fluxes. This model simulation utilizes a substantially improved (over previous POLCOMS applications) river flow database composed of $\sim 300$ rivers discharging into the region, gauged at up to daily frequency. The simulation period is from 1 January to 31 December 2001 and a multiyear (19982001) simulation of the POLCOMS Atlantic Margin Model at $\sim 12 \mathrm{~km}$ resolution (AMM; Figure 1) provides initial conditions and contemporary boundary data for HRCS (AMM is in turn forced by the North Atlantic FOAM Model [Bell et al., 2000]). The boundary data consist of hourly elevations and depth mean currents, and daily depthvarying currents, temperature and salinity. These data are imposed around the irregular open boundary (chosen to follow the $200 \mathrm{~m}$ isobath apart from where it crosses the Norwegian Trench) using a flux/radiation scheme for the barotropic component and an up-wind advection scheme for temperature and salinity. The inclusion of the momentum advection term at the velocity points next to the open boundary acts as a "Sommerfeld" type boundary condition [Sommerfeld, 1949], which facilitates the propagation of energy out of the domain. The results from AMM also provide a comparison with a coarser resolution model.

[12] Experiments with an application of POLCOMS to the seas west of the UK [Holt and James, 2006] demonstrated the utility of a scale selective horizontal diffusion formulation in preventing excessive baroclinic eddy activity in open stratified waters during the summer. Hence all the experiments here use a Laplacian diffusion term (on s-levels), with a diffusivity calculated following Smagorinsky [1963] and a horizontal turbulent Prandtl number of 2.0. Holt and James [2006] demonstrate a particular sensitivity of the baroclinic eddy field produced by the model to the arbitrary parameter in the Smagorinsky formulation, $\alpha=0.2$ in this work (this value was also used by Young et al. [2004]). Hence this parameter sensitivity needs to be kept in 
Table 1. Description of the Three Model Experiments

\begin{tabular}{|c|c|c|c|c|c|}
\hline Experiment & Description & $\begin{array}{c}\text { Temperature and } \\
\text { Salinity } \\
\text { Integration }\end{array}$ & $\begin{array}{l}\text { Surface } \\
\text { Forcing }\end{array}$ & $\begin{array}{c}\text { Boundary } \\
\text { Forcing }\end{array}$ & $\begin{array}{c}\text { River } \\
\text { Forcing }\end{array}$ \\
\hline 1 & full baroclinic & yes & yes & yes & yes \\
\hline 2 & full barotropic & no & yes & yes & no \\
\hline 3 & $\begin{array}{l}\text { barotropic } \\
\text { tidal/oceanic } \\
\text { forcing }\end{array}$ & no & no & yes & no \\
\hline
\end{tabular}

mind when considering the fine scale currents presented here. Holt and James [2006] also present an investigation of horizontal pressure gradient error in eddy-permitting s-coordinate models, demonstrating that calculating this term by interpolation onto horizontal planes (as is the case here), along with scale selective horizontal diffusivity, substantially reduces this error.

[13] Three 1-year-long model experiments, listed in Table 1, are considered here. All these experiments use identical open boundary forcing including any baroclinic effects, since these experiments are not run for AMM. By sequentially subtracting the results of these experiments we can divide the currents into density $\left(\mathrm{u}_{\mathrm{D}}\right)$, barotropic-wind $\left(\mathrm{u}_{\mathrm{W}}\right)$ and barotropic-oceanic $\left(\mathrm{u}_{\mathrm{O}}\right)$ driven components. Labeling the experiments with subscripts 1,2 , and 3 :

$$
\begin{aligned}
& \mathbf{u}_{D}=\mathbf{u}_{1}-\mathbf{u}_{2} \\
& \mathbf{u}_{w}=\mathbf{u}_{2}-\mathbf{u}_{3} \\
& \mathbf{u}_{O}=\mathbf{u}_{3} \\
& \mathbf{u}=\mathbf{u}_{1} \\
& \text { so } \\
& \mathbf{u}=\mathbf{u}_{D}+\mathbf{u}_{W}+\mathbf{u}_{O}
\end{aligned}
$$

Dividing the currents in this way does not separate out the nonlinear effects; thus it is only an approximate indication of the relative importance of the terms, and none of these components are independent of the others. For example, in addition to the currents that result directly from internal pressure fields, which can be estimated from the thermal wind equations (discussed later), the density component includes any current speed that results from stratification reducing the frictional effects on the wind-driven circulation.

[14] POLCOMS applications on the northwest European shelf, has been validated against a wide range of observations; the model data comparison presented by Holt et al. [2005] used an application of the model (MRCS) differing only in resolution (four times coarser horizontally and with fewer vertical levels than HRCS) and compared the model results with extensive observations from the 1988-89 North Sea Project [Charnock et al., 1994], AVHRR and historical current meters and tide gauges. Improved forcing (boundary conditions and river fluxes), might be expected to lead to an improvement in the simulation (this has been confirmed for the residual current and salinity simulation in MRCS, not reported here); it is our intention to repeat this comprehensive validation exercise with HRCS in the near future. However, issues relating to surface flux and vertical mixing parameterizations are likely to remain, for example the tendency to underestimate the thermocline depth. A brief comparison with the 1829 high-resolution CTD casts available for 2001 in the model domain (primarily in the North Sea and Skagerrak) from the ICES database (http://www.

\begin{tabular}{|c|c|c|c|c|c|c|c|c|c|c|c|}
\hline \multirow{2}{*}{$\begin{array}{c}\text { Drifter } \\
\text { Id }\end{array}$} & \multirow{2}{*}{$\begin{array}{l}\text { Start } \\
\text { Day }\end{array}$} & \multirow{2}{*}{$\begin{array}{c}\text { Longitude, } \\
\text { E }\end{array}$} & \multirow{2}{*}{$\begin{array}{c}\text { Latitude, } \\
\text { N }\end{array}$} & \multirow{2}{*}{$\begin{array}{c}\text { Duration, } \\
\text { Days }\end{array}$} & \multicolumn{2}{|c|}{ Drifter Mean } & \multicolumn{2}{|c|}{ Model Mean } & \multirow{2}{*}{$\begin{array}{c}\text { Speed, } \\
\text { RMS Error } \\
\mathrm{ms}^{-1}\end{array}$} & \multirow{2}{*}{$\begin{array}{l}\text { Direction, } \\
\text { RMS Error }{ }^{\circ} \mathrm{T}\end{array}$} & \multirow[b]{2}{*}{ Observations } \\
\hline & & & & & Speed, $\mathrm{ms}^{-1}$ & Direction, ${ }^{\circ} \mathrm{T}$ & Speed, $\mathrm{ms}^{-1}$ & Direction, ${ }^{\circ} \mathrm{T}$ & & & \\
\hline 21576 & 212 & -9.7 & 54.4 & 27 & 0.04 & 65.6 & 0.05 & 61.0 & 0.03 & 55.1 & 13 \\
\hline 24058 & 212 & -11.0 & 53.8 & 14 & 0.05 & 71.7 & 0.03 & 359.0 & 0.06 & 93.7 & 13 \\
\hline 26118 & 211 & -9.3 & 54.9 & 33 & 0.07 & 47.4 & 0.08 & 26.5 & 0.06 & 55.1 & 32 \\
\hline 27231 & 212 & -10.5 & 54.0 & 8 & 0.10 & 45.0 & 0.09 & 34.3 & 0.06 & 20.3 & 5 \\
\hline 4384 & 212 & -10.4 & 53.5 & 9 & 0.05 & 13.1 & 0.06 & 8.9 & 0.04 & 93.7 & 9 \\
\hline 7971 & 211 & -8.4 & 55.4 & 15 & 0.06 & 80.7 & 0.09 & 63.9 & 0.06 & 48.3 & 8 \\
\hline 13678 & 183 & 4.8 & 55.9 & 13 & 0.03 & 71.7 & 0.04 & 189.9 & 0.01 & 52.5 & 2 \\
\hline 13680 & 182 & 3.4 & 55.6 & 60 & 0.09 & 62.9 & 0.02 & 30.7 & 0.10 & 71.3 & 20 \\
\hline 13685 & 182 & 3.4 & 55.7 & 57 & 0.12 & 49.6 & 0.03 & 35.5 & 0.12 & 72.1 & 28 \\
\hline 13689 & 182 & 3.4 & 55.8 & 27 & 0.05 & 72.2 & 0.02 & 138.4 & 0.17 & 83.5 & 15 \\
\hline 13692 & 182 & 4.0 & 55.7 & 8 & 0.04 & 53.2 & 0.03 & 74.9 & 0.03 & 43.7 & 6 \\
\hline 15347 & 182 & 3.4 & 55.9 & 62 & 0.06 & 22.3 & 0.04 & 2.9 & 0.10 & 81.7 & 62 \\
\hline 15360 & 182 & 4.0 & 55.9 & 56 & 0.04 & 40.3 & 0.03 & 50.6 & 0.03 & 62.8 & 56 \\
\hline 15377 & 182 & 2.8 & 55.6 & 54 & 0.03 & 81.7 & 0.02 & 97.7 & 0.03 & 56.4 & 15 \\
\hline 15395 & 182 & 4.0 & 56.0 & 55 & 0.03 & 42.5 & 0.02 & 57.1 & 0.04 & 86.3 & 55 \\
\hline 15399 & 181 & 2.7 & 55.7 & 55 & 0.04 & 68.3 & 0.02 & 83.0 & 0.04 & 77.5 & 49 \\
\hline 15407 & 181 & 2.1 & 55.4 & 49 & 0.02 & 88.4 & 0.03 & 87.7 & 0.02 & 48.2 & 13 \\
\hline 15438 & 181 & 2.2 & 55.5 & 55 & 0.04 & 78.5 & 0.02 & 83.9 & 0.04 & 84.4 & 43 \\
\hline 28122 & 184 & 4.9 & 56.0 & 30 & 0.06 & 55.6 & 0.04 & 44.4 & 0.06 & 53.2 & 29 \\
\hline 28123 & 183 & 4.8 & 56.1 & 54 & 0.09 & 47.6 & 0.05 & 49.0 & 0.09 & 68.5 & 54 \\
\hline 28124 & 182 & 2.8 & 55.5 & 54 & 0.02 & 57.7 & 0.02 & 135.7 & 0.07 & 74.3 & 10 \\
\hline 28125 & 181 & 2.1 & 55.3 & 54 & 0.03 & 104.2 & 0.00 & 25.5 & 0.07 & 77.9 & 12 \\
\hline 28128 & 182 & 4.1 & 55.8 & 56 & 0.04 & 50.4 & 0.04 & 59.5 & 0.04 & 70.6 & 46 \\
\hline 28129 & 182 & 3.3 & 55.8 & 43 & 0.11 & 66.2 & 0.02 & 76.6 & 0.17 & 89.6 & 38 \\
\hline 28130 & 182 & 4.0 & 56.0 & 55 & 0.02 & 32.9 & 0.02 & 38.7 & 0.03 & 74.4 & 55 \\
\hline Overall & & & & 978 & & & & & 0.08 & 73.8 & 688 \\
\hline
\end{tabular}
ices.dk/ocean/dotnet/HydChem/HydChem.aspx) gives an RMS and mean error of $1.1^{\circ} \mathrm{C}$ and $-0.6^{\circ} \mathrm{C}$ (model too cool) respectively; i.e., similar uncertainties to those presented by Holt et al. [2005] for the southern North Sea.

Table 2. Statistics of Velocities Calculated From the Drifter Tracks Shown in Figure 2 and the Corresponding Model Values 


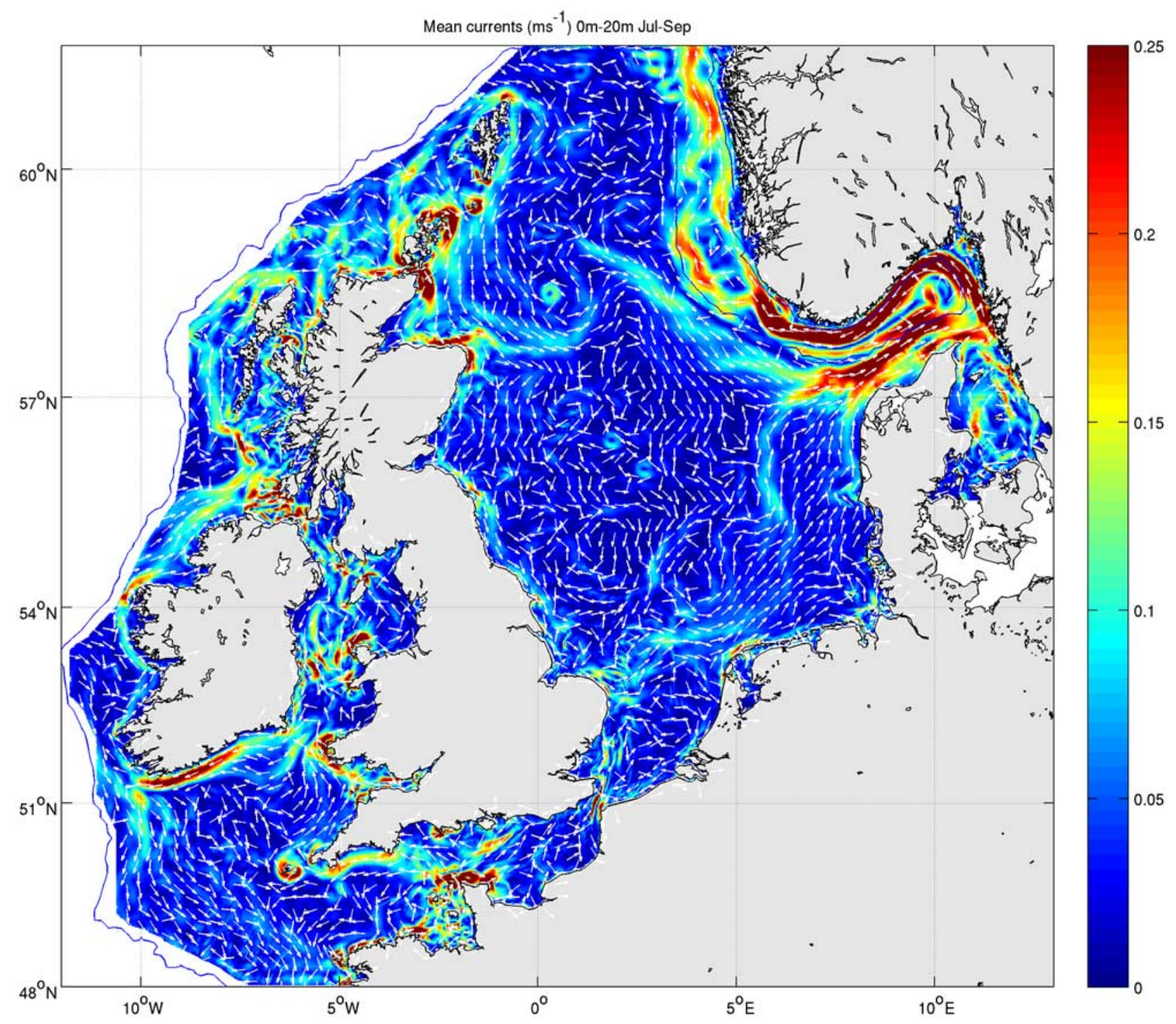

Figure 4a. Summer mean horizontal circulation averaged: (a) near surface $(0-20 \mathrm{~m})$, (b) middepth $(20-40 \mathrm{~m})$, and (c) bottom (40-m seabed). For clarity only velocity vectors at every 12 th grid points are shown. The color shading indicates current speeds and is from the full resolution model results.

[15] To estimate the accuracy of the modeled residual currents, velocity estimates from 26 Argos Satellite tracked drifting buoys (Figure 2) deployed in the summer of 2001 by the Centre for Environment, Fisheries and Aquaculture Science (CEFAS) and The Irish Marine Institute (RV Corystes: cruise 6 and RV Celtic Voyager: cruise 34) are compared with the corresponding model currents. The drifters have a $5.5 \mathrm{~m}$ drogue centered at $30 \mathrm{~m}$ depth. Subtidal drifter velocities are estimated using a method similar to that described by Horsburgh et al. [2000]. The drifter positions are linearly interpolated to give an hourly time series. This is filtered using a Doodson X0 filter $[I O C, 1985]$ to remove energy at semidiurnal and diurnal tidal frequencies. Velocities are then calculated by finite difference and averaged to give daily $25 \mathrm{~h}$ means. After measurements below $0.01 \mathrm{~ms}^{-1}$ and in water depths shallower than $40 \mathrm{~m}$ have been removed this provides a total of 688 velocity measurements. The model currents, averaged between 20 and $40 \mathrm{~m}$ depths, at the corresponding horizontal location and time are extracted to give a direct comparison (Table 2).

\section{Shelf Scale Circulation}

[16] The subtidal currents $(25 \mathrm{~h}$ means centered on 11:30UTC) averaged for July to September and over the depth interval: (1) top $20 \mathrm{~m}$, (2) $20 \mathrm{~m}$ to $40 \mathrm{~m}$, and (3) $40 \mathrm{~m}$ to seabed are shown in Figure 4. These summer mean currents demonstrate that the modeled North Sea circulation closely matches that shown in Figure 2 in many respects, although much of the density-driven circulation captured by high-resolution observations, such as the flow around Dogger Bank [Brown et al., 1999; Lwiza et al., 1991], is missing from Figure 2. These high-resolution model results indicate that the circulation across the shelf is made of many small scale structures; the largest currents appear as filament-like jets, with high spatial coherence. An exception is 


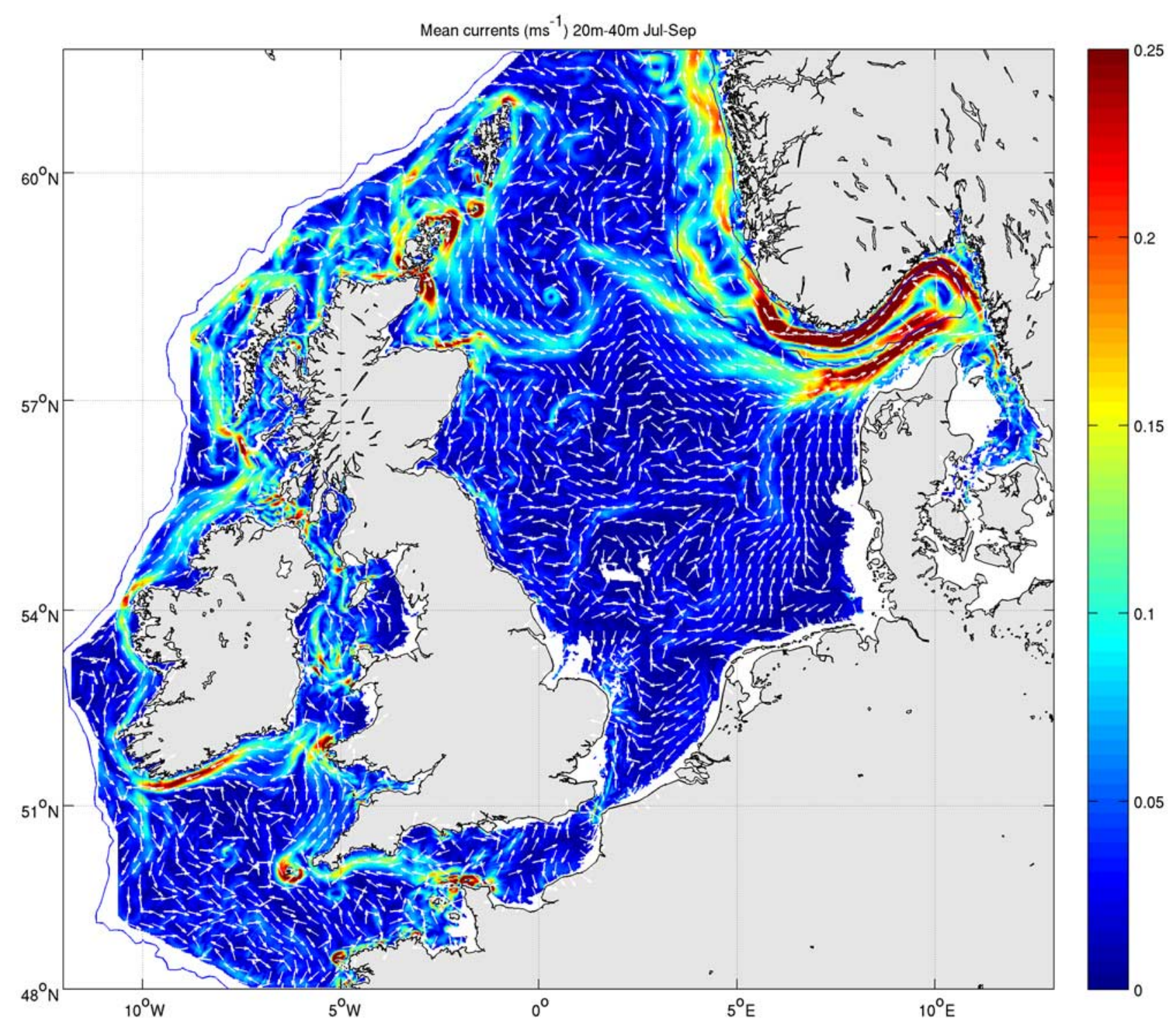

Figure 4b. See caption on Figure 4a.

in the southern North Sea from January to March (not shown) where there is little structure to the broad eastward current. In all seasons, water from the North Sea enters the Skagerrak in three distinct branches: from the north the Dooley Current [Lwiza et al., 1991; Svendsen et al., 1991] retroflects to join the current along the western side of the Norwegian Trench, along the $40 \mathrm{~m}$ isobath east of Dogger Bank, and in a northward current close to the Danish coast. These currents all join to follow the steep topography around the Skagerrak and form the Norwegian Costal Current, augmented by fresher water from the Baltic. The Norwegian Coastal Current is the strongest current in the region and contains two persistent eddy features at $\sim 58.9^{\circ} \mathrm{N}$ (comparable to those observed by Johannessen et al. [1989]). The shape of the Dooley current seen in Figure 4a is very similar to that shown by Svendsen et al. [1991] and corresponds to the $100 \mathrm{~m}$ isobath, indicating a role of topography in steering the current most probably through the tendency of the flow to conserve potential vorticity and follow flh contours. Comparing Figures $4 a, 4 b$, and $4 c$ it can be seen that much of the northern North Sea circulation does not vary greatly with depth, for example the topographically steered eddy north of the Dooley current is barotropic as previously identified from observations by Svendsen et al. [1991]. The clockwise circulation around Dogger Bank is more apparent in the $20-40 \mathrm{~m}$ depth interval (Figure $4 \mathrm{~b}$ ) than at the surface. An important feature that is apparent in the near bottom currents (Figure 4c), but not seen at the surface, is the Atlantic inflow on the west side of the Norwegian Trench.

[17] On the western side of the model domain, from Brittany in the south to the Fair Isle Channel north of Scotland, the currents generally follow the coastline (flowing with the coast on the right), except where the currents separate from the coast to follow the fronts in the English Channel, St. George's Channel and North Channel. At each 


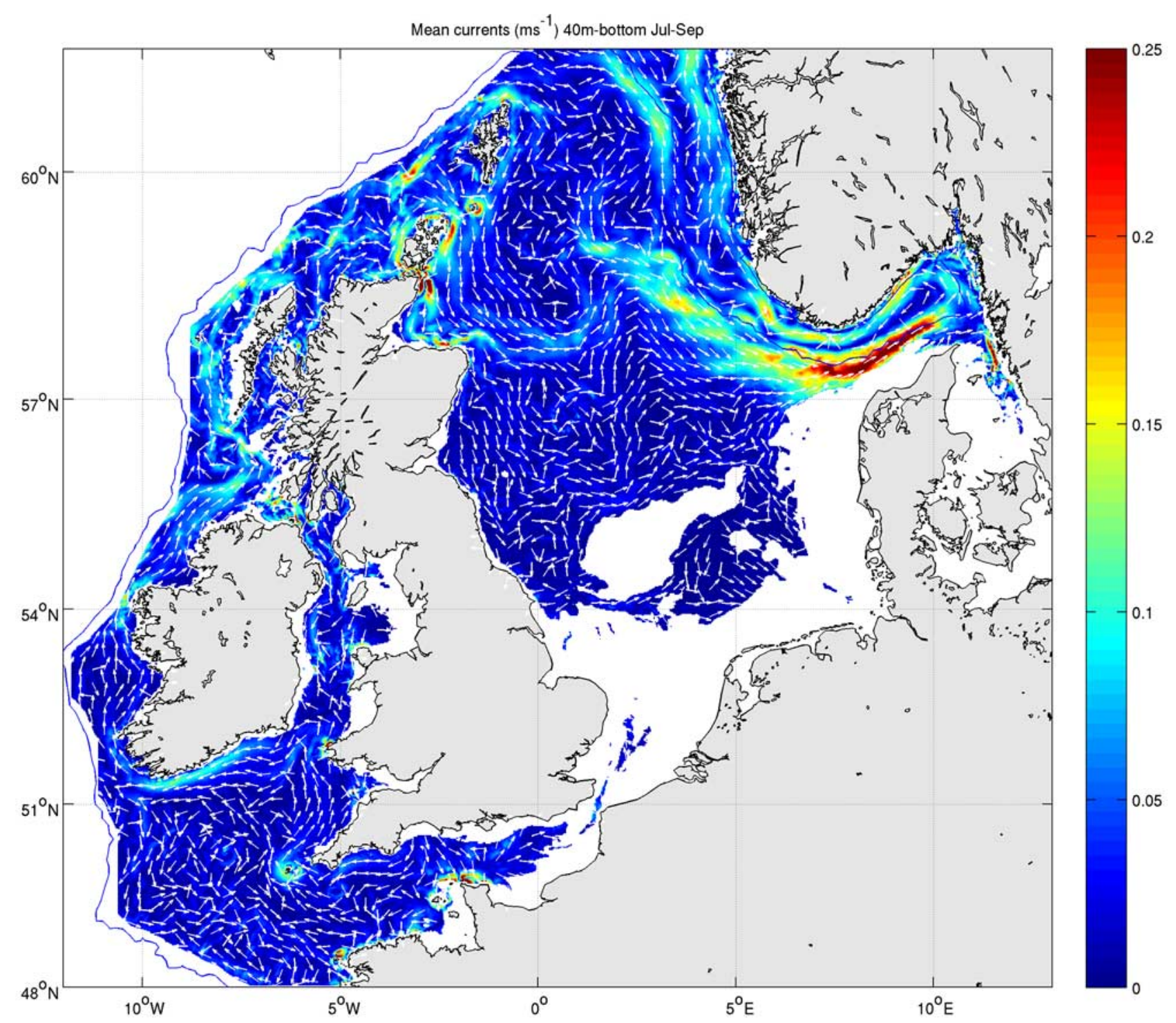

Figure 4c. See caption on Figure 4a.

of these fronts, the flow structure is complex owing both to eddy activity at the front and tidal rectification at the headlands [Pingree et al., 1982]. Particularly apparent is the Irish Coastal current [Fernand et al., 2006] and the St. George's Channel frontal jet [Brown et al., 2003]. The jet across the English Channel is less well defined because the front there extends close to the Cherbourg Peninsular, and the frontal flow is masked by the strong tidally rectified flow in this region.

[18] To examine the structure of the currents in the North Sea in more detail, Figure 5 shows vertical cross-sections of currents and density ( $25 \mathrm{~h}$ mean on 1 August 2001; chosen to represent the peak of the summer heating cycle) along a section from the Dutch coast to the Shetlands (section A in Figure 1). The density section (Figure 5a) shows the Rhine plume, a number of tidal mixing fronts and temperature stratified regions with reasonably flat pycnoclines. A qualitative comparison with undulating CTD (Scanfish) obser- vations from the central North Sea [Brown et al., 1999, Figure 7] suggests that the vertical structure is reasonably well represented: the pyconocline is between 20 and $40 \mathrm{~m}$ deep in the observations and 14 and $35 \mathrm{~m}$ in this model; i.e., its width is well represented but the pycnocline is too shallow in common with similar model studies in this region [e.g., Luyten et al., 2003]. However, this comparison is probably an exceptional case as Scanfish observations in other regions [e.g. Figure 5, in Brown et al., 1999] generally show a much sharper pycnocline than the model.

[19] The across section currents (Figure 5b) have a complex structure both in the vertical, and along the section, where there are a number of reversals to the generally eastward current. When the density-driven component is estimated from Equation 2 (Figure 5c), it is evident that it accounts for many of the currents seen here and in most cases is in the same direction as the total current. 

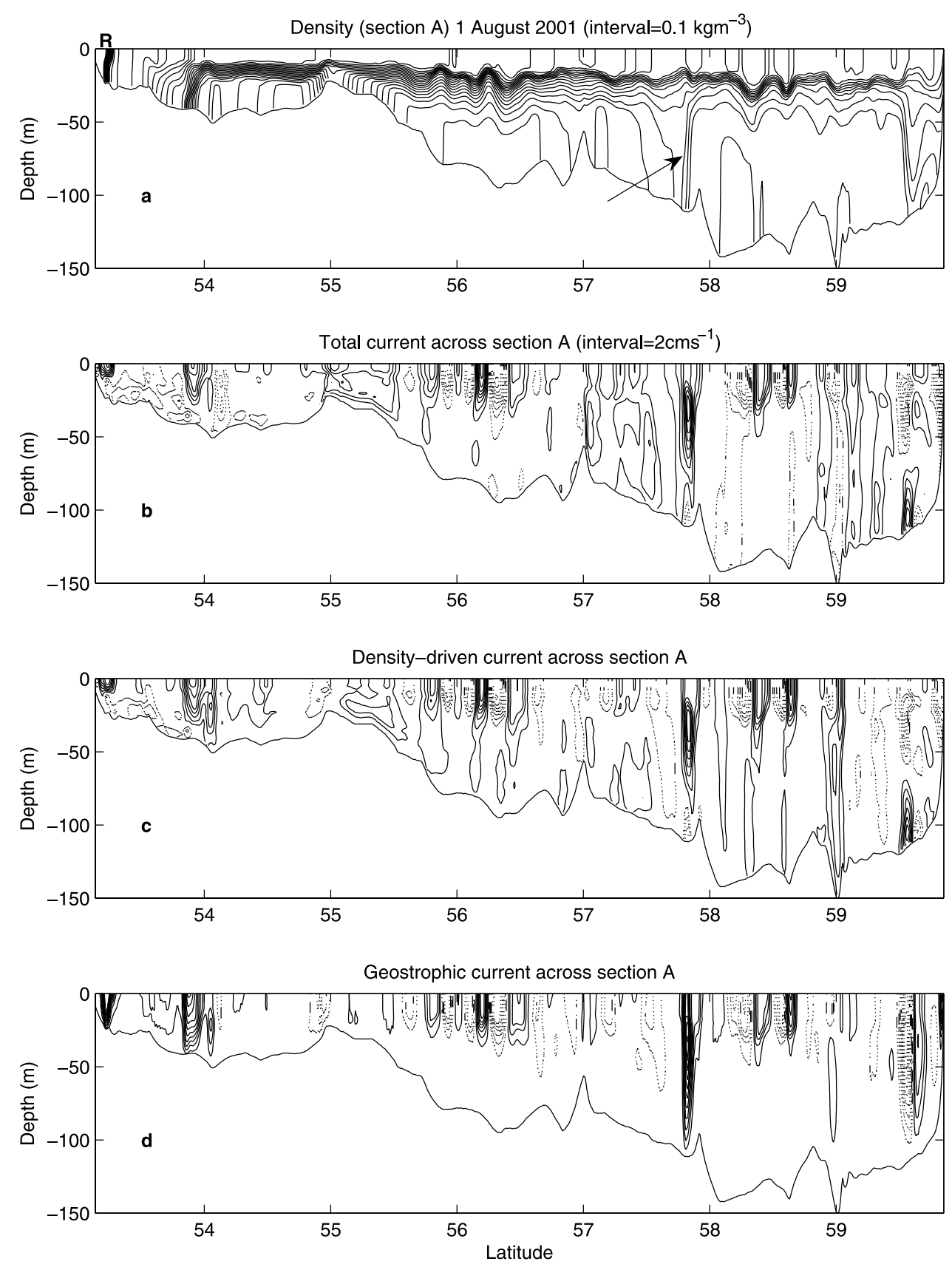

Figure 5. Vertical section from the Dutch coast (south) to the Shetland Isles (north) of density and currents, across section A (Figure 1) for 1 August 2001. Eastward flow is shown as solid contours, westward as dotted. The interval is $0.02 \mathrm{~ms}^{-1}$. (a) Density, (b) across-section total current, (c) acrosssection density-driven component $\left(\mathbf{u}_{\mathrm{D}}\right)$, and (d) geostrophic current, $\left(\mathbf{u}_{\mathrm{g}}\right)$. The Rhine plume is marked by $\mathrm{R}$ and the Dooley current bottom front is marked by an arrow at $\sim 57.7^{\circ} \mathrm{N}$.

[20] It is enlightening to see what proportion of this density component is directly attributable to a geostrophic balance with the local density field. This can be estimated by integrating the thermal wind equations:

$$
\frac{\partial u_{g}}{\partial z}=\frac{g}{\rho f} \frac{\partial \rho}{\partial y} \quad \frac{\partial v_{g}}{\partial z}=-\frac{g}{\rho f} \frac{\partial \rho}{\partial x},
$$

assuming zero current at the seabed (the density component is very small here except near the coast).The geostrophic component is estimated in this way since it matches the method used in observational studies (as justified by Hill [1996]). This geostrophic component correlates well with the full density-driven component (for this section $r^{2}=0.72$ at the surface and 0.49 overall), although there are significant differences in the amplitude of the currents. For example the maximum density-driven component in the Dooley Current is $\sim 0.16 \mathrm{~ms}^{-1}$ compared with a maximum of $0.22 \mathrm{~ms}^{-1}$ in the geostrophic component. The Dooley Current occurs close to a bottom front (marked by an arrow 


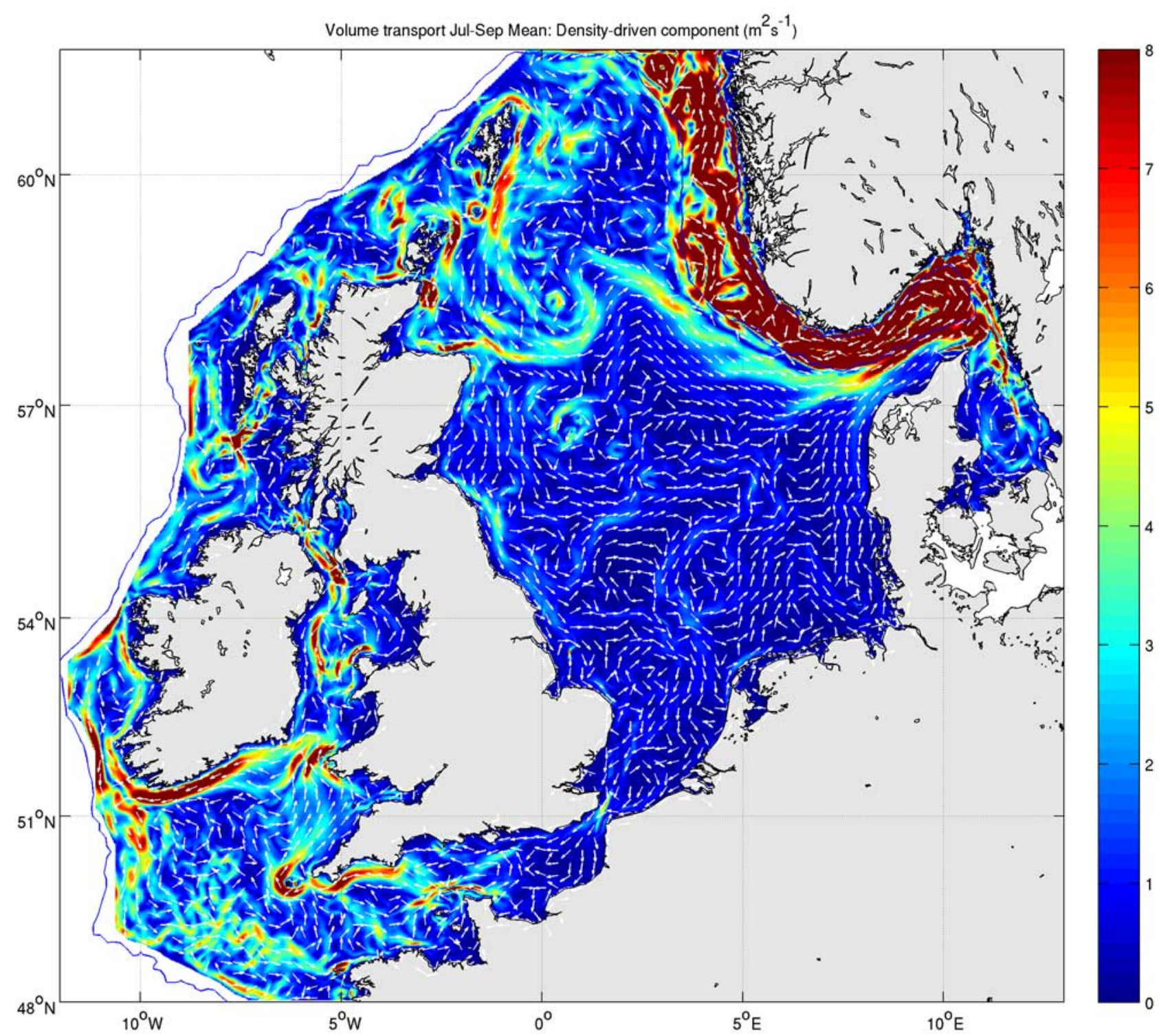

Figure 6a. Depth integrated volume transport averaged from July to September. Density-driven component. For clarity only vectors at every 12 th grid points are shown.

on Figure 5a), and the density and current structure seen at this location is very similar to that observed by Svendsen et al. [1991]. The current here can be explained as an interaction between the barotropic wind/oceanic-driven circulation and the density field. A topographically steered barotropic current is present here throughout the year. As stratification develops in the spring, the shear generated by this current forms a bottom front. The resulting density field accelerates a current in the same direction that is stronger than the original barotropic current.

[21] Many of the smaller scale structures seen in both the density component of the current and the geostrophic estimate (e.g., between $55.7^{\circ} \mathrm{N}$ and $56.6^{\circ} \mathrm{N}$ ) can be attributed to anticyclonic baroclinic eddies seen in the daily mean surface current fields (not shown).

[22] The comparison with drifter velocity measurements (Table 2) indicates that the RMS difference between the average observed and modeled speed for each drifter is
$0.034 \mathrm{~ms}^{-1}$ (a fractional error of $\sim 46 \%$ ), but this is consistently biased to the model underestimating the mean speed. The RMS difference between the individual daily mean modeled and observed speeds is $\sim 0.08 \mathrm{~ms}^{-1}$, a percentage error of $\sim 80 \%$. Indicating that, while the current speeds averaged over $\sim 40 \mathrm{~d}$ are reasonably well modeled, the higher frequency variability is less accurately simulated. The RMS difference between the observed and modeled average direction for each drifter is $39^{\circ} \mathrm{T}$. Examining the distribution of errors in the direction indicates that, of the 688 individual observations, $\sim 50 \%$ are accurate to $\pm 45^{\circ} \mathrm{T}$ and $\sim 80 \%$ are accurate to $\pm 90^{\circ} \mathrm{T}$.

\section{Volume Transport}

[23] The depth integrated volume fluxes $(\langle\overline{\mathbf{u}} h\rangle$; where brackets indicate a time average) give a useful indication of the capacity of these currents to transport material, e.g., 


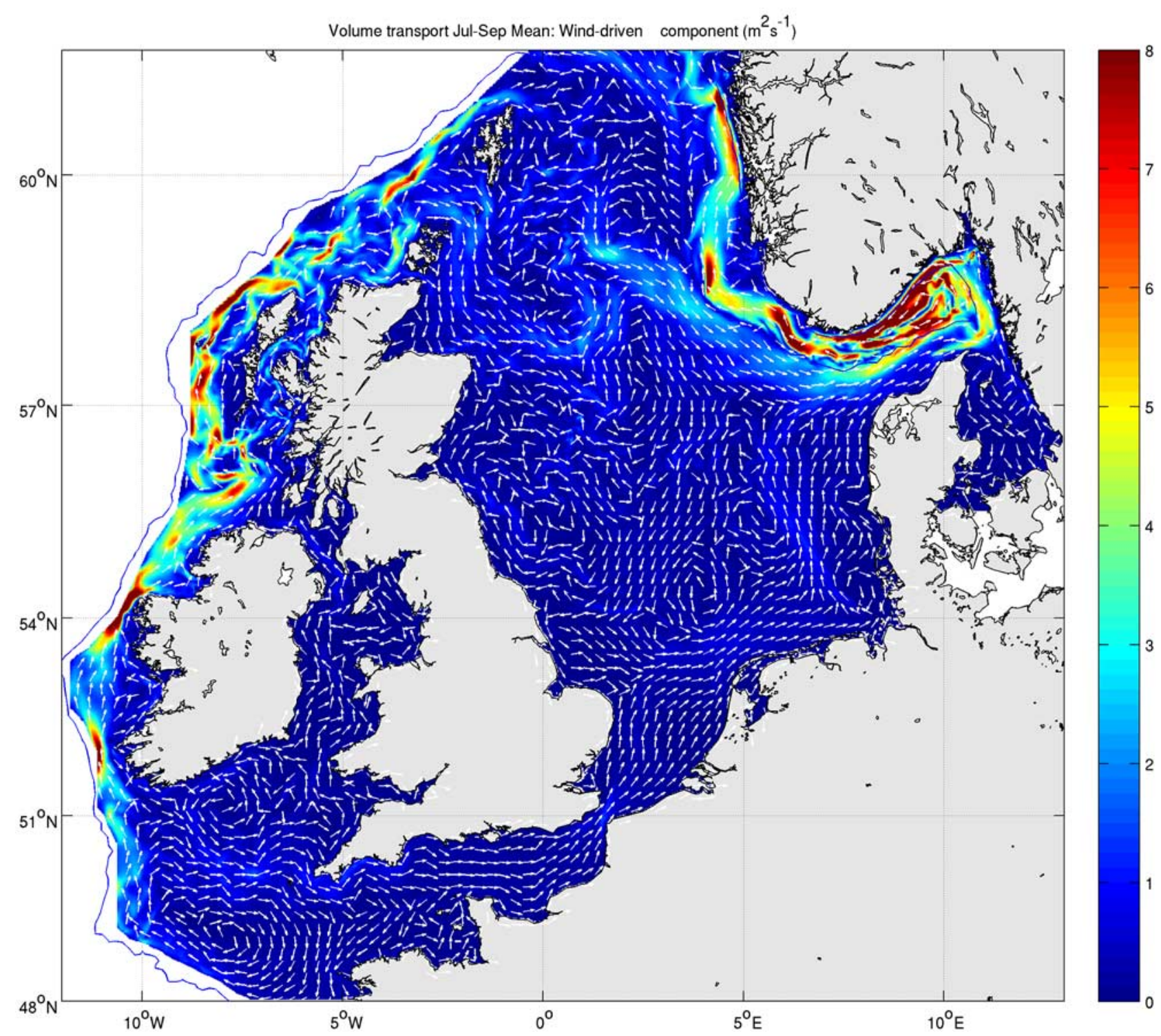

Figure 6b. Depth integrated volume transport averaged from July to September. Wind-driven component. For clarity only vectors at every 12 th grid points are shown.

nutrients, suspended material, contaminants and biota. This is only an approximate indication since correlations between the spatial and temporal current and concentration structure are often important. The volume transport can be divided into density, wind driven and oceanic components as in equation (2) and the summer mean of each of these (Figures 6a-6c) shows a distinct spatial structure. The density component (Figure 6a) is demonstrably the dominant constituent across most of the shelf in this season: the average magnitude of the density-driven transport over the model domain is $2.5 \mathrm{~m}^{2} \mathrm{~s}^{-1}$ compared with $1.9 \mathrm{~m}^{2} \mathrm{~s}^{-1}$ for the oceanic-driven and $0.8 \mathrm{~m}^{2} \mathrm{~s}^{-1}$ for the wind-driven components. The density-driven component shows significantly more fine scale structure than the wind- or oceanicdriven components and is responsible for most of the sinuous jets seen in Figure 4. Both the wind- and oceanicdriven components (Figures $6 \mathrm{~b}-6 \mathrm{c}$ ) show transport with a much larger (across-flow) horizontal scale, consistent with the propagation of barotropic coastally trapped waves (see below), but as is seen later this does not necessarily result in greater transport across sections.

[24] To examine the temporal variation of the transport, Figure 7 demonstrates how the volume flux across section A, (Figure 1) varies over the annual cycle. Values for the three components of velocity (equation (2)) are shown. In each component, there is a predominantly eastward transport, but with a very different temporal and spatial structure. The wind-driven component (Figure 7a) has a high degree of temporal variability, but strong spatial coherence along the section; this variability reflects the synoptic scale atmospheric forcing. The lack of spatial variability possibly reflects the coarse resolution of the ECMWF atmospheric model data; at $1^{\circ}$ resolution, any effects of the horizontal structure of weather systems are not well represented. The strongest wind-driven fluxes are in bands south of $54^{\circ} \mathrm{N}$, between $56.8^{\circ} \mathrm{N}$ and $58.2^{\circ} \mathrm{N}$ and north of $59^{\circ} \mathrm{N}$. Occasional westward fluxes are apparent in each of these bands. There is a weak seasonal cycle, with strongest fluxes in winter and 


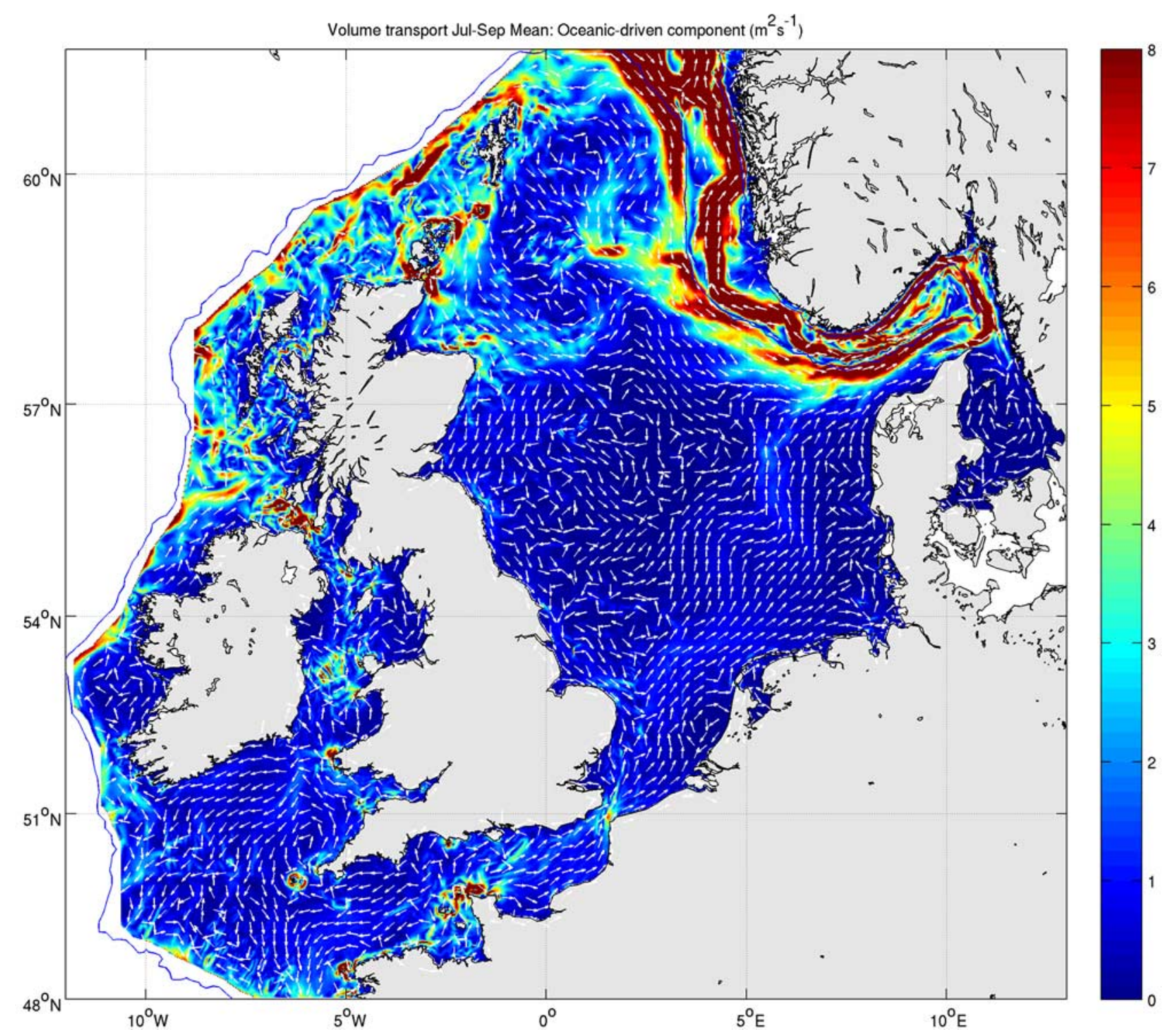

Figure 6c. Depth integrated volume transport averaged from July to September. Oceanic-driven component. For clarity only vectors at every 12 th grid points are shown.

autumn. The oceanic-driven component (Figure 7c) shows currents at very similar locations to the wind driven component. This component is made up of the residual oceanic forcing and tidal rectification by frictional and advective processes on the shelf, so it is modulated by the spring-neap cycle in near coastal waters and includes the effects of headland eddies close to the coast (e.g., the westward flow around the southern tip of the Shetland Isles at the northern end of section A).

[25] In contrast to the wind- and oceanic-driven components, the density-driven component of the volume flux (Figure 7b) occurs on seasonal scales and is comparatively slowly varying. The average volume transport from July to September for section A is presented in Figure 8 in two parts (A1 and A2). At the southern end of the section (A2) the transport of the Rhine plume is evident in the density-driven component, which makes the largest contribution to the total. North of this is a broad eastward current with both oceanic- and wind-driven components. The horizontal scale of this broad eastward current is $\sim 86 \mathrm{~km}$, which is consistent with a barotropic coastally trapped wave $\left((\mathrm{gh})^{0.5} / \mathrm{f} \sim 100 \mathrm{~km}\right)$. North of the broad wind- and oceanic-driven current is a tight eastward density driven jet of width $\sim 16 \mathrm{~km}$ at the southern tidal mixing front. On the south flank of Dogger Bank is a broader westward density-driven current, while north of Dogger Bank is the eastward current observed by Brown et al. [1999]. The dominant feature in section A1 is the Dooley current between $57.5^{\circ} \mathrm{N}$ and $58^{\circ} \mathrm{N}$. This is made up of all three components, with the density-driven component being the largest. The westward transport north of $58^{\circ} \mathrm{N}$ is associated with the retroflection of the Dooley current seen in Figure 4 and is almost entirely densitydriven. The ratio of the mean flux to its standard deviation for July to September gives an indication of the variability of the transport across this section. For the southern section (A2) this is 0.62 for the total flux, 0.20 for the 

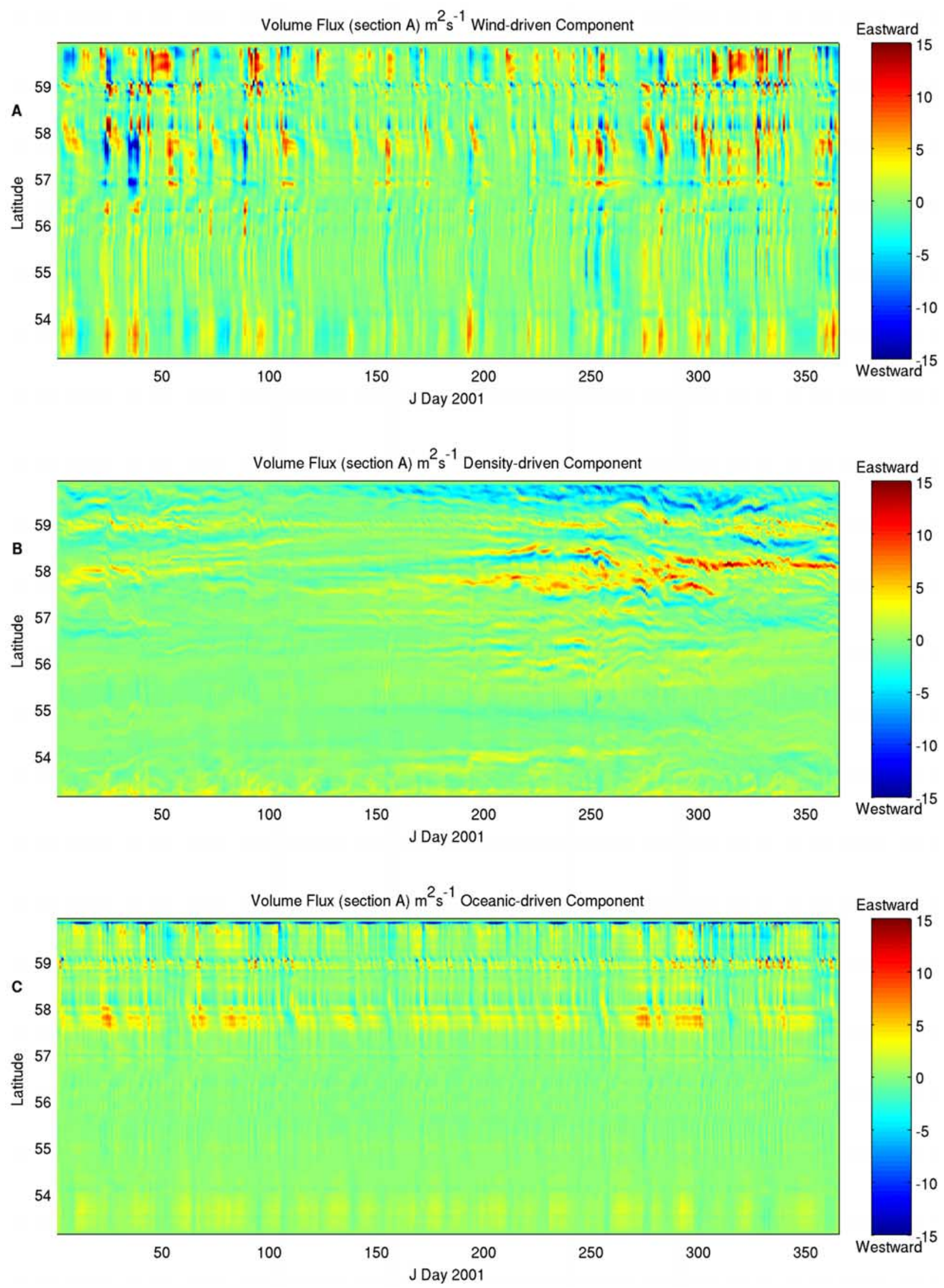

Figure 7. Time series of depth mean transport across section A: (a) wind-driven component, (b) densitydriven component, and (c) oceanic-driven component. 

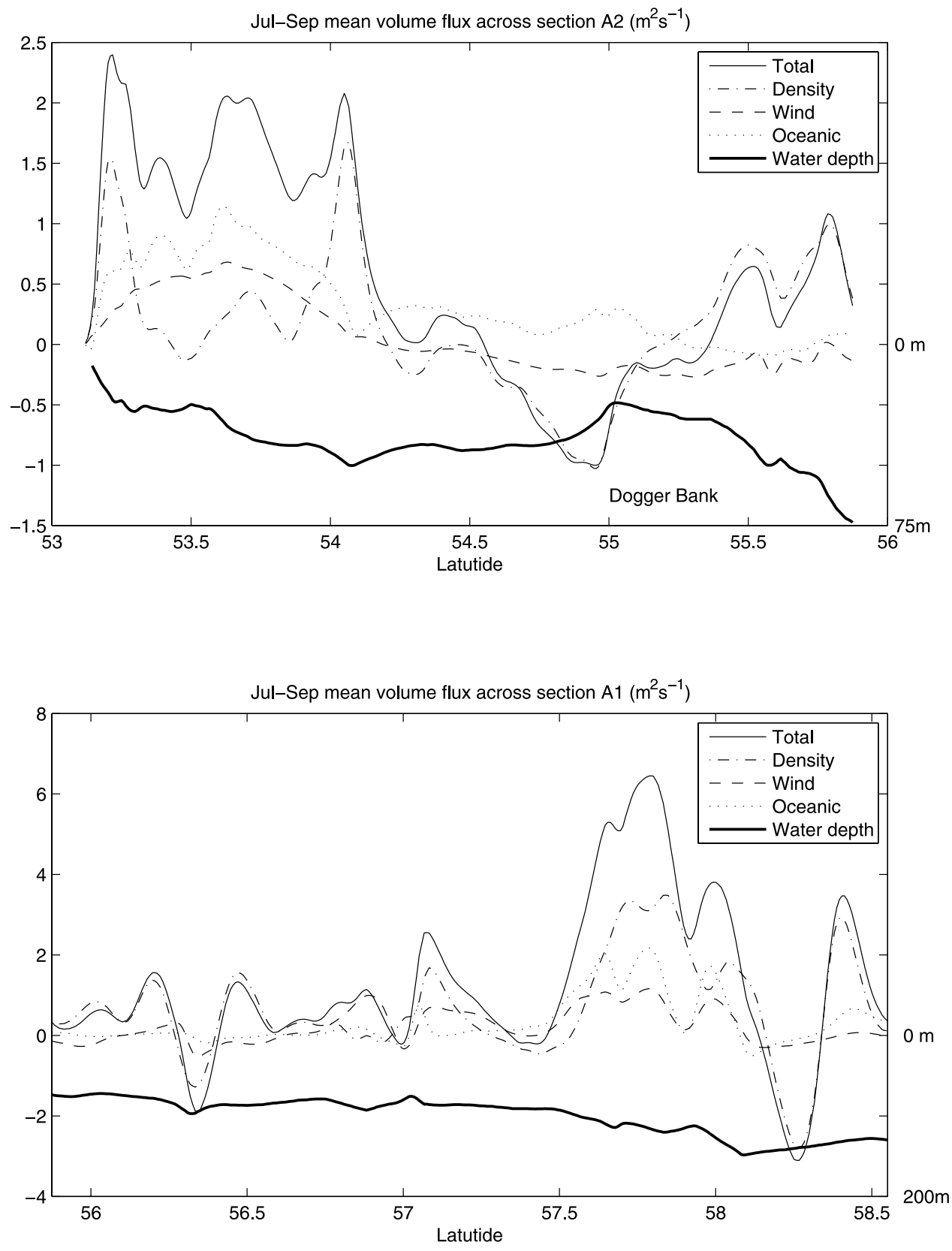

Figure 8. Components of the summer mean volume flux across section A2 (southern North Sea); section A1 (central and northern North Sea). Positive values indicate eastward flow. The depth scale is shown on the right hand axis.

wind-driven component, 0.7 for the density-driven component and 1.22 for the oceanic-driven component. For the northern section (A1) these ratios are: total 0.79 ; wind 0.21 ; density 0.69 ; oceanic 0.69 . These results confirm that the wind component is substantially more variable that the other two.

[26] The strongest density-driven component of the flux across section A (Figure 7b) is in the late summer/autumn and examining the seasonal evolution of the stratification (Figure 9) indicates that this corresponds to regions of high gradient in potential energy anomaly that arise during the breakdown of stratification. This breakdown takes a number of months, so the corresponding currents are persistent, but vary in position. A prominent feature in this density-driven flux is at $\sim 58^{\circ} \mathrm{N}$ (Figure 7), corresponding to the northern flank of the Dooley current. There is no well-defined tidal mixing front in this region; however, as noted in section 3 (Figure 5) there is enhanced mixing and a bottom front here; Figure 9 shows a minimum in potential energy anomaly at $\sim 57.5^{\circ} \mathrm{N}$ from about day 250 , and that stratification between $57^{\circ} \mathrm{N}$ and $58^{\circ} \mathrm{N}$ breaks down significantly earlier than the regions to the north or south, about day 300 compared with 350 . This region of reduced stratification occurs as the front near the east coast of Scotland migrates eastward forming an intrusion into the main stratified region of the northern North Sea (Figure 11 shows how the frontal 


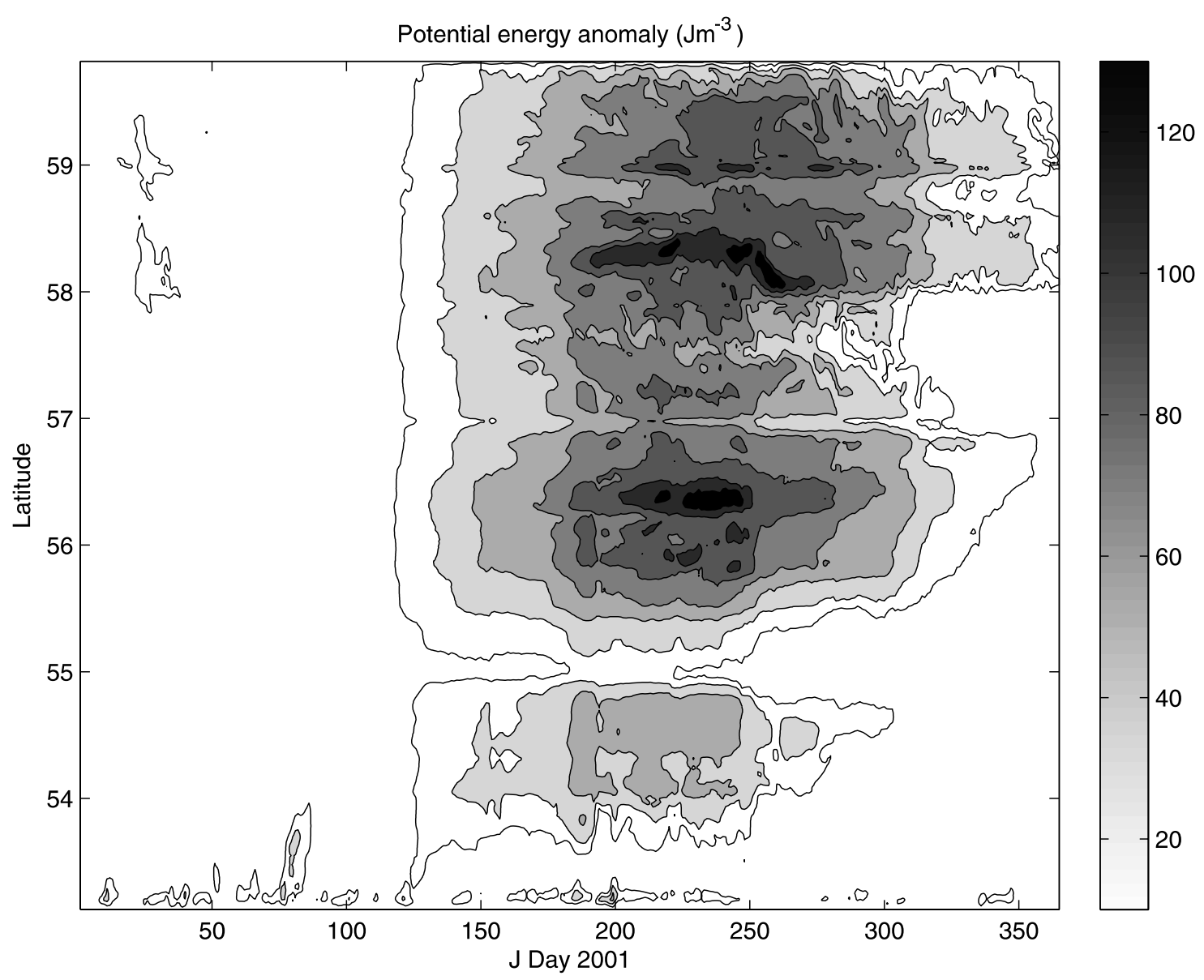

Figure 9. Time evolution of the potential energy anomaly along section A.

positions change with time). The intense density component of the Dooley current $\left(\sim 58^{\circ} \mathrm{N}\right)$ is on the northern flank of this region of enhanced mixing and moves northward, with time, following the front as the intrusion progresses eastward.

[27] To examine the resolution dependence of these volume transports, Figure 10 compares the fluxes across section A for the $1.8 \mathrm{~km}$ resolution model (HRCS) and the $12 \mathrm{~km}$ model (AMM), which supplies the boundary conditions. There is good agreement between the large scale fluxes in the two cases, as would be expected for currents in geostrophic balance and determined by the large-scale pressure gradients. However, there are a number of important differences. In the southern part of the section, the eastward flow near the continental coast is composed of at least three distinct jets in the higher resolution model because of the better resolution of the frontal structures here. Similarly, the westward flow south of Dogger Bank is more clearly defined. In the northern part there is again significantly more fine scale variability in the high resolution model, but also the location of the Dooley current is shifted southwards in the $1.8 \mathrm{~km}$ model compared with the $12 \mathrm{~km}$ model, although the strength is very similar. This shift arises from the minimum in potential energy anomaly being moved southwards in HRCS compared with AMM. The flow reversal north of the Dooley current is hardly seen in the $12 \mathrm{~km}$ model, again arising from changes in the details of the stratification relative to this section.

[28] To examine the volume fluxes in other regions of the shelf and to compare the overall importance of the various components, the seasonal mean transports across all of the sections shown in Figure 12 are listed in Tables 3-5. During the winter months (January to March) the oceanicdriven, and in some cases wind-driven components, tend to dominate. The density-driven component is significant in a number of regions during this season, particularly at the shelf edge where it tends to retard the total transport; this is seen throughout the year for the Irish Shelf section. At the Hebrides shelf and Irish shelf sections in winter, the windand density-driven components are in close balance leaving the oceanic-driven (boundary condition) component to closely match the total transport. The density-driven component becomes more positive in spring and summer. Examining the spatial variation of the flux across the Irish shelf section (see Figure 6a for the summer fluxes) demonstrates that close to the coast the density component is in a narrow northward and eastward coastal jet as is expected from the Irish coastal current [Fernand et al., 2006], but across the shelf to the edge of the model domain is a southward and westward density-driven component. This discrepancy is most likely a result of the proximity of the open boundary and one possible explanation is that there is 

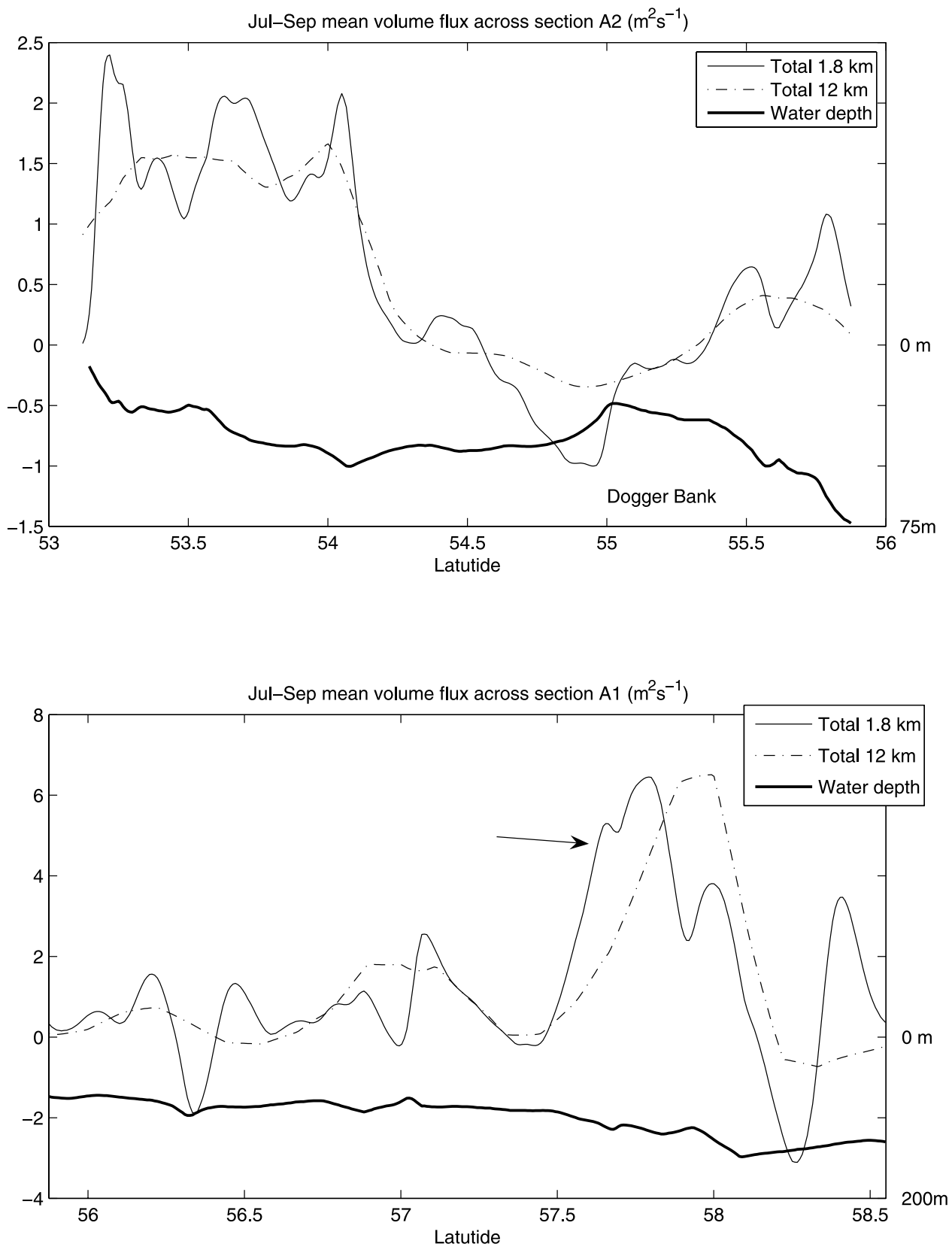

Figure 10. Summer mean volume flux across section A2 (southern North Sea) and section A1 (central and northern North Sea) from the $1.8 \mathrm{~km}$ (HRCS) and $12 \mathrm{~km}$ (AMM) resolution models. The Dooley Current in HRCS is indicated by an arrow.

a significant (negative) density component in the boundary condition sea level, which is balanced by the internal pressure gradient term in the full model but not in experiments two and three; this sea level gradient would tend to increase the along-shelf current in these experiments and appear in equation (2) as a retarding density-driven component.

[29] During the winter (Table 3), the wind-driven component tends to retard the North Sea inflow and to a lesser extent the Dooley current. This retardation is because of a predominance of northward winds during the winter. These winds arise from passing low pressure systems (cyclones), which tend to decrease in strength as they move from west to east; i.e., in the eastern part of this domain the cyclones have stronger leading northward winds than trailing southward winds. A similar, but weaker, effect is also seen in the autumn (Table 6).

[30] The density-driven component increases in the spring, and, during the summer, it yields a substantial fraction of most of the fluxes listed in Table 5. This component is proportionately weakest on the Irish and Hebrides shelves and strongest at the entrance to the St. George's Channel. During the autumn the wind-driven component is substantially more important, although the density-driven component remains significant. 
Table 3. Winter (January-March) Mean Transports Across the Sections Shown in Figure 12; the Direction of Positive Fluxes is That Shown by the Arrows in This Figure

\begin{tabular}{|c|c|c|c|c|c|}
\hline Transport (Sv.) & HRCS & AMM & Wind & Density & Oceanic \\
\hline 1. Entering Skagerrak & 0.30 & 0.14 & .02 & 0.02 & 0.25 \\
\hline 2. Southern Nort & 21 & 2 & & & 0.11 \\
\hline 3. South of Dogger bank & .07 & 07 & 03 & & 0.03 \\
\hline 4. North of Dogger bank & 0.02 & 0.02 & .03 & -0.01 & 0.00 \\
\hline 5. Western North Sea & 0.09 & 0.10 & 0.06 & 0.04 & -0.01 \\
\hline 6. Dooley current & 0.1 & 21 & -0 & & 0.16 \\
\hline 7. North & 0.3 & 0.43 & -0.13 & -0 & 0.52 \\
\hline 8. Fair is & 0.3 & 0 & 0.07 & -0 & 0.31 \\
\hline 9. Hebrides & 0.47 & 0.64 & 0.12 & -0 & 0.45 \\
\hline 10. Iris & & & & -0 & 0.28 \\
\hline $\begin{array}{l}\text { 11. St. George's channel } \\
\text { inflow }\end{array}$ & 0.15 & 0.17 & 0.02 & 0.05 & 0.09 \\
\hline $\begin{array}{l}\text { 12. St. George's channel } \\
\text { outflow }\end{array}$ & 0 & 0.13 & 0.06 & 0.06 & 0.01 \\
\hline $\begin{array}{l}\text { 13. English channel } \\
\text { inflow }\end{array}$ & 001 & 0.02 & 0.00 & .00 & 0.01 \\
\hline $\begin{array}{l}\text { 14. English channel } \\
\text { outflow }\end{array}$ & 0.01 & 0.03 & 0.05 & 0.00 & -0 \\
\hline 15. Dover straits & 0.13 & 0.10 & 0.06 & -0.01 & 0.08 \\
\hline
\end{tabular}

[31] Volume transport estimates from the AMM model and observational estimates from the literature are also given in Table 5. It is apparent from these results that the HRCS $(1.8 \mathrm{~km})$ and AMM $(12 \mathrm{~km})$ models give very similar results for many of these currents. The clearest difference between the two models is the tendency for the AMM to underestimate the flow into the Skaggerak during the summer and autumn. The differences between the two models do not appear to be correlated with the importance of the density-driven circulation, indicating that the $12 \mathrm{~km}$ resolution model is able to reproduce many of the largescale density-driven flows.

[32] The results presented in Table 5 show that the HRCS model transports agree well with the available literature estimates of volume flux and, while these estimates are from sparse measurements, different periods and not exactly colocated with the model sections, they provide a semiquantitative validation of the model results, particularly that it reproduces the relative strengths of currents reasonably well. Both the Fair Isle Current and the North Sea inflow

Table 4. Spring (April-June) Mean Transports, as Table 3

\begin{tabular}{lccccc}
\hline Transport (Sv.) & HRCS & AMM & Wind & Density & Oceanic \\
\hline 1. Entering Skagerrak & 0.53 & 0.71 & 0.13 & 0.22 & 0.19 \\
2. Southern North Sea & 0.15 & 0.14 & 0.02 & 0.04 & 0.08 \\
3. South of Dogger bank & 0.01 & -0.01 & 0.00 & 0.02 & -0.02 \\
4. North of Dogger bank & 0.01 & 0.00 & -0.01 & 0.01 & 0.00 \\
5. Western North Sea & 0.08 & 0.07 & 0.00 & 0.06 & 0.02 \\
6. Dooley current & 0.20 & 0.23 & 0.08 & 0.03 & 0.08 \\
7. North Sea inflow & 0.54 & 0.57 & 0.01 & 0.08 & 0.45 \\
8. Fair isle current & 0.34 & 0.27 & 0.13 & 0.02 & 0.18 \\
9. Hebrides shelf & 0.36 & 0.43 & 0.18 & -0.06 & 0.24 \\
10. Irish shelf & 0.13 & 0.06 & 0.10 & -0.08 & 0.11 \\
11. St. George's channel & 0.20 & 0.14 & 0.00 & 0.11 & 0.08 \\
$\quad$ inflow & & & & & \\
12. St. George's channel & 0.16 & 0.11 & 0.00 & 0.13 & 0.02 \\
$\quad$ outflow & & & & & \\
13. English channel inflow & 0.10 & 0.08 & -0.02 & 0.10 & 0.02 \\
14. English channel outflow & 0.02 & 0.01 & 0.00 & 0.07 & -0.04 \\
15. Dover straits & 0.06 & 0.04 & 0.01 & -0.03 & 0.08 \\
\hline
\end{tabular}

Table 5. Summer (July-September) Mean Transport, as Table $3^{\mathrm{a}}$

\begin{tabular}{|c|c|c|c|c|c|c|}
\hline Transport (Sv.) & HRCS & AMM & Wind & Density & Oceanic & Observed \\
\hline $\begin{array}{l}\text { 1. Entering } \\
\text { Skagerrak }\end{array}$ & 1.24 & 0.99 & 0.13 & 0.91 & 0.20 & $1.0 \pm 0.5^{1}$ \\
\hline $\begin{array}{l}\text { 2. Southern } \\
\text { North Sea }\end{array}$ & 0.20 & 0.19 & 0.05 & 0.06 & 0.09 & \\
\hline $\begin{array}{l}\text { 3. South of Dogger } \\
\text { bank }\end{array}$ & 0.04 & 0.02 & 0.02 & 0.04 & -0.02 & \\
\hline $\begin{array}{l}\text { 4. North of Dogger } \\
\text { bank }\end{array}$ & 0.03 & 0.02 & -0.01 & 0.04 & 0.00 & $0.05^{2}$ \\
\hline 5. Western North Sea & 0.11 & 0.09 & 0.00 & 0.09 & 0.02 & \\
\hline 6. Dool & 0.34 & 0.34 & 0.07 & 0.17 & 0.10 & $0.25 \pm 0.13^{3}$ \\
\hline 7. Nort & 0.71 & 0.66 & 0.00 & 0. & 0.46 & \\
\hline 8. Fair is & 0.39 & 0.27 & 0.09 & 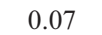 & 0.23 & $0.2^{4}$ \\
\hline 9. Hebride & 0.54 & 0.59 & 0.18 & 0.0 & 0.30 & $0.25^{5}$ \\
\hline 10. Irish shelf & 0.24 & 0.16 & 0.16 & -0.05 & 0.13 & $0.25^{6}$ \\
\hline $\begin{array}{l}\text { 11. St. George's } \\
\text { channel inflow }\end{array}$ & 0.31 & 0.26 & 0.01 & 0.21 & 0.10 & $0.27^{7}$ \\
\hline $\begin{array}{l}\text { 12. St. George's } \\
\text { channel outflow }\end{array}$ & 0.25 & 0.20 & 0.01 & 0.22 & 0.02 & \\
\hline $\begin{array}{l}\text { 13. English channel } \\
\text { inflow }\end{array}$ & 0.17 & 0.17 & 0.03 & 10 & 0.02 & \\
\hline $\begin{array}{l}\text { 14. English channel } \\
\text { outflow }\end{array}$ & 0.08 & 0.08 & -0.01 & 0.14 & -0.05 & \\
\hline 15. Dover straits & 0.06 & 0.04 & 0.02 & -0.04 & 0.08 & $0.094^{8}$ \\
\hline
\end{tabular}

15. Dover straits $\quad \begin{array}{lllllll}0.06 & 0.04 & 0.02 & -0.04 & 0.08 & 0.094^{8}\end{array}$

a Observations are taken from: ${ }^{1}$ Danielssen et al. $[1997],{ }^{2}$ Brown et al.
1999], ${ }^{3}$ Svendsen et al. [1991], ${ }^{4}$ Turrell et al. [1992], from the FRS currents meter records shown by ${ }^{5}$ Holt et al. [2001], ${ }^{6}$ Fernand et al. [2006],

are apparently overestimated, although the modeled flow into the Skagerrak is within the error bounds given by Danielssen et al. [1997] and close to the model estimates given by Roed and Fossum [2004]. It is somewhat reassuring that the one section that is co-located in space and from the same year as the model run (section 10 across the Irish Shelf) gives good agreement with the observations from Fernand et al. [2006].

\section{Conclusion}

[33] These results demonstrate the diversity of structure, and in time and space scales of shelf sea currents, which is only realizable through model simulations that include motions at the scale of the baroclinic Rossby radius. Wind, density and oceanic forcing are found to play an approxi-

Table 6. Autumn (October-December) Mean Transports, as Table 3

\begin{tabular}{lccccc}
\hline Transport (Sv.) & HRCS & AMM & Wind & Density & Oceanic \\
\hline 1. Entering Skagerrak & 1.50 & 1.18 & 0.26 & 0.97 & 0.27 \\
2. Southern North Sea & 0.21 & 0.23 & 0.12 & 0.03 & 0.06 \\
3. South of Dogger bank & 0.03 & 0.03 & 0.01 & 0.00 & 0.01 \\
4. North of Dogger bank & 0.04 & 0.03 & 0.02 & 0.03 & 0.00 \\
5. Western North Sea & 0.21 & 0.18 & 0.11 & 0.09 & 0.01 \\
6. Dooley current & 0.36 & 0.38 & 0.12 & 0.13 & 0.11 \\
7. North Sea inflow & 0.80 & 0.84 & -0.01 & 0.09 & 0.72 \\
8. Fair Isle current & 0.56 & 0.47 & 0.32 & 0.08 & 0.16 \\
9. Hebrides shelf & 0.75 & 0.85 & 0.50 & 0.06 & 0.20 \\
10. Irish shelf & 0.42 & 0.38 & 0.34 & -0.04 & 0.12 \\
11. St. George's & 0.30 & 0.28 & 0.02 & 0.16 & 0.12 \\
$\quad$ channel inflow & & & & & \\
12. St. George's & 0.22 & 0.13 & 0.01 & 0.19 & 0.02 \\
$\quad$ channel outflow & & & & & \\
13. English channel inflow & 0.07 & 0.07 & -0.05 & 0.09 & 0.03 \\
14. English channel outflow & 0.01 & -0.01 & 0.01 & -0.05 & 0.05 \\
15. Dover straits & 0.04 & 0.04 & 0.04 & -0.04 & 0.04 \\
\hline
\end{tabular}




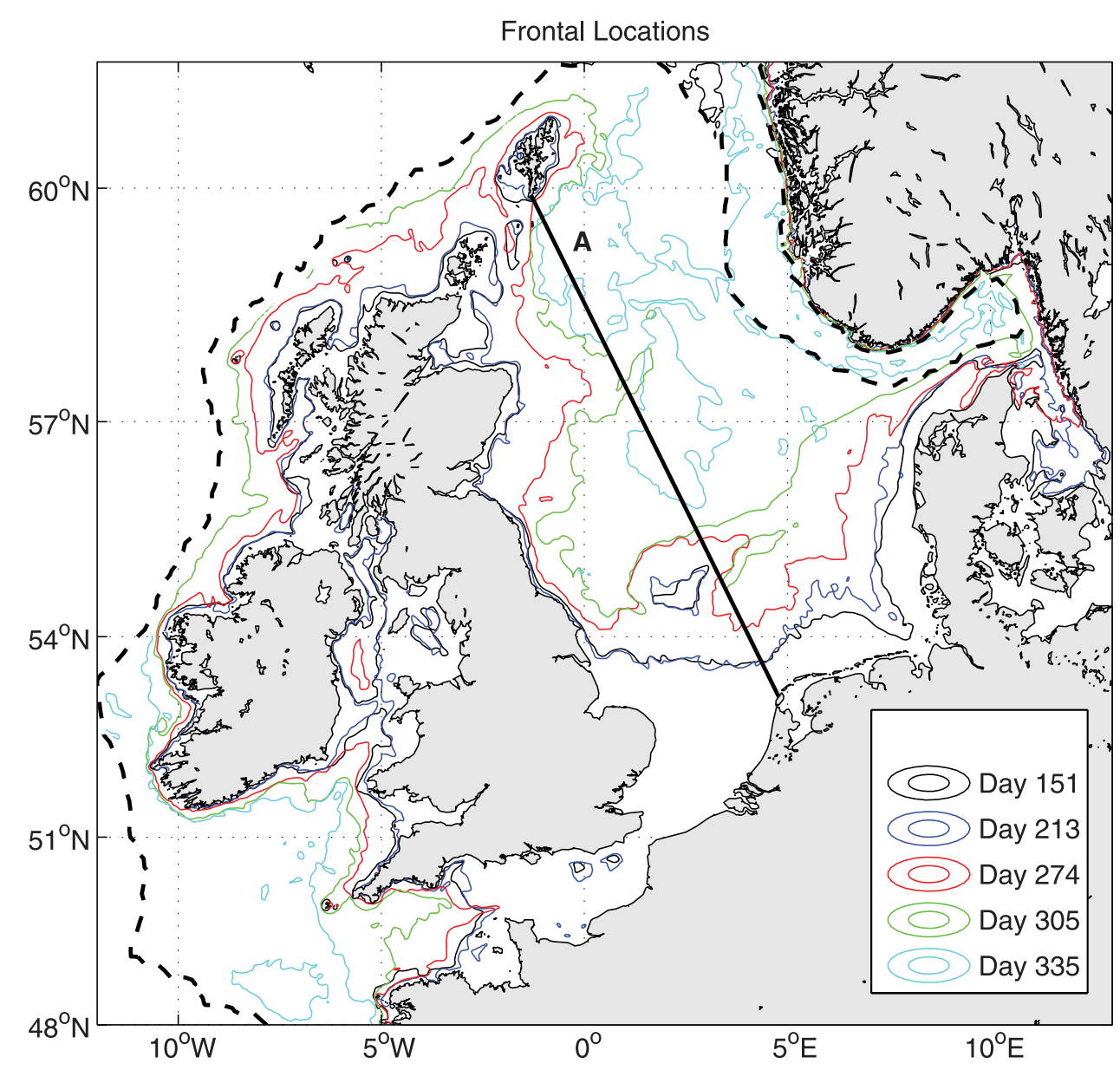

Figure 11. Frontal positions (defined by the $1{ }^{\circ} \mathrm{C}$ surface to bottom temperature difference contour) at the indicated year-day. The heavy solid line shows the location of section A and the dashed line the $200 \mathrm{~m}$ isobath.

mately equal role in the overall circulation pattern in these shelf seas. For example, annual transport associated with the Dooley Current is found to be $24 \%$ wind-driven, $34 \%$ density-driven and $42 \%$ determined by the external boundary conditions; in the summer this changes to $20 \%$ wind, $50 \%$ density and $30 \%$ external. These results are in general agreement with the conclusion of Huthnance [1997] that there is "strong external control" on the North Sea circulation. The importance in the northern North Sea of the density-driven currents during the break down of stratification in late summer and autumn has been demonstrated. Many studies [e.g., Brown et al., 2003] have focused on the importance of density-driven currents at well-defined (and well-located) tidal mixing fronts. As the wind increases and convective mixing is introduced during the autumn, these fronts, and their corresponding currents migrate across the shelf (Figure 11) and persist over a number of months; in many regions, the stratification is not completely broken down until December. These results suggest that the effects of the density-driven circulation are more wide-ranging both in terms of time and space than the fixed location of tidal mixing fronts might suggest (Figure 11).

[34] Direct comparisons with subsurface velocities estimated from 26 satellite tracked drifters indicate that the modeled velocities are accurate to $\sim 46 \%$ when averaged over the drifter tracks of $\sim 40 \mathrm{~d}$ duration, compared with daily mean errors of $\sim 80 \%$. However, the average currents are negatively biased (model too slow). This somewhat contradicts the comparison with literature estimates of transport (Table 5), which suggest the model overestimates the transport into the Skagerrak. Given these are subsurface observations during the summer, the source of this bias is most likely an under-estimation of the horizontal density gradients and consequently the density component of the velocity. This suggests these model simulations put a lower bound on the importance of the density driven flow to the transport in the North Sea.

[35] The surface and benthic boundary layers play an important role in determining the density field throughout the year, and the present results demonstrate that the accurate modeling of vertical mixing is crucially important to the modeling of shelf sea circulation. The details of the results presented here inevitably depend on the particular turbulence closure scheme used (in this case a MellorYamada Level 2.5 closure scheme with an algebraic mixing length and the stability functions given by Deleersnijder and Luyten [1994]), and it is often the case that the break down of stratification is less well modeled than its onset [e.g., Luyten et al., 2003]. This discrepancy arises from inaccuracies in modeling mixing (particularly convection) 


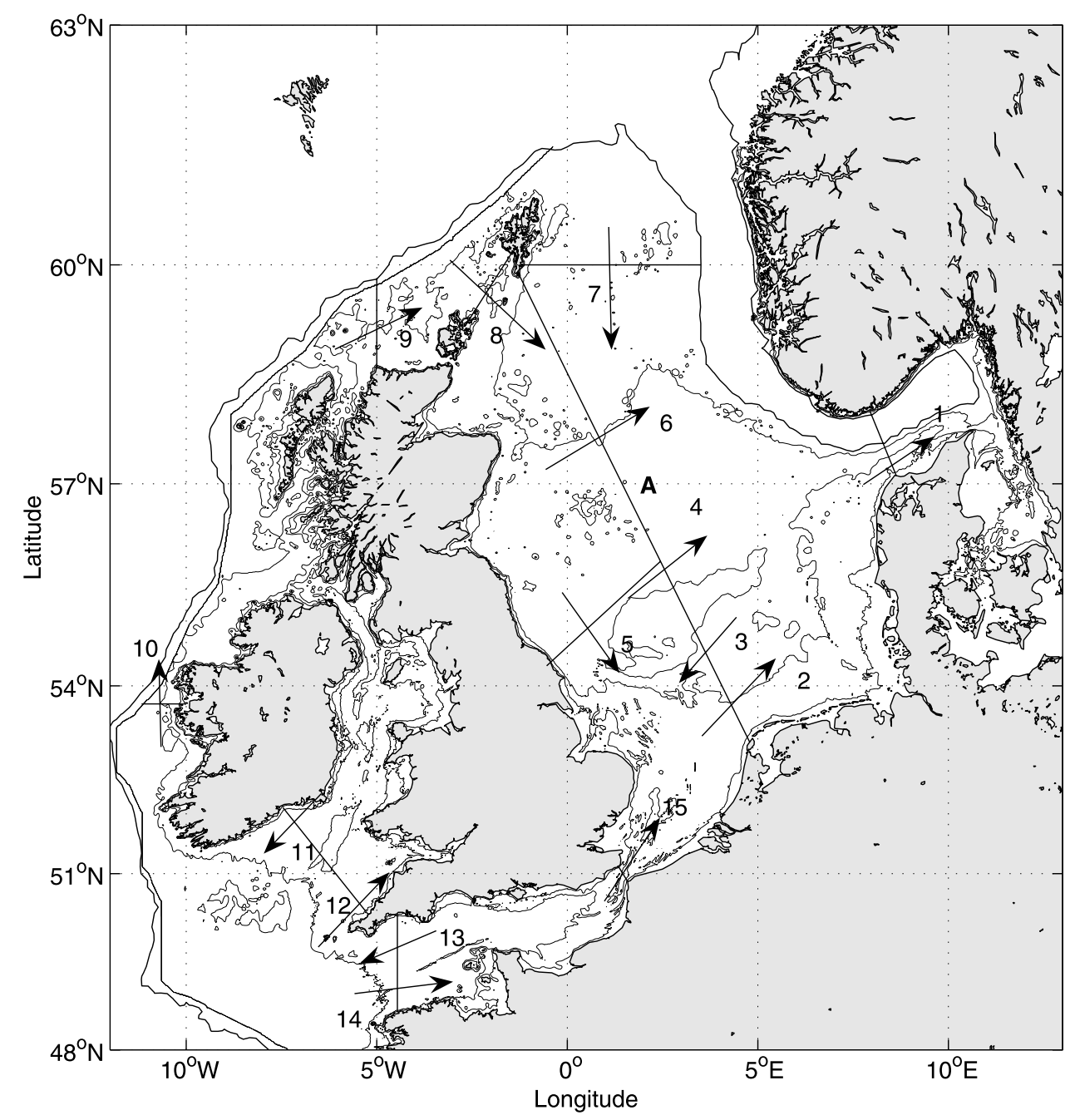

Figure 12. Sections used for volume flux calculations.

in stratified environments and the need for accurate surface forcing, since the breakdown of stratification often depends on the occurrence of individual storm events.

[36] The $12 \mathrm{~km}$ AMM model used for boundary conditions is shown to give good agreement with the $1.8 \mathrm{~km}$ HRCS model in the large scale circulation; the main differences are in the details of currents near fronts, at the open boundary, and the flow entering the Skagerrak. This result gives us some confidence that the coarse-resolution model reproduces the large scale circulation features reasonably well in studies where high-resolution is not yet practical, for example in multidecadal simulations and when coupled to complex ecosystem models. However, it does imply that resolution as fine as HRCS is required to simulate some important shelf sea phenomena. For example, to investigate any relationship between the transport of nutrients by frontal jets and enhanced biological production at fronts [e.g., Pingree et al., 1982; Richardson et al., 2000].

[37] This work has not addressed the critical issue of lateral mixing between coastal waters and water of Atlantic origin, which determines the overall exchange of material between the land and open-ocean. Such a study requires more than a single annual cycle to be simulated, since the flushing time of the North Sea is a substantial fraction of a year; for example Huthnance [1997] suggests a value of $\sim 290$ d, while model estimates by Lenhart and Pohlmann [1997] suggest 167 d. Such a study is presently underway.

[38] Acknowledgments. This work was funded by POL's core science program, Met. Office contract PB/B3648 and EU-MERSEA-IP (SIP3CT-2003-502885). The high performance computing aspects of this work were greatly aided by the assistance of Mike Ashworth (Science and Technology Facilities Council, Daresbury Laboratory); the simulations were conducted on 256 IBM Power 5 processors on the UK HPCx system. We thank Juan Brown (British Oceanographic Data Centre) for some very useful comments on the text. The drifter data used in this study is from CEFAS and the Irish Marine Institute cruises on RV Corystes (cruise 6) and RV Celtic Voyager (cruise 34), obtained from BODC. We are very grateful that this data has been made available to us.

\section{References}

Backhaus, J. O., and D. Hainbucher (1987), A finite-difference general circulation model for shelf seas and its application to low frequency variability on the north European shelf, in Three-Dimensional Models of Marine and Estuarine Dynamics, Oceanography Series, vol. 45, edited by J. C. J. Nihoul and B. M. Jamart, pp. 221-244, Elsevier, New York.

Bell, M. J., R. M. Forbes, and A. Hines (2000), Assessment of the FOAM global data assimilation system for real time operational ocean forecasting, J. Mar. Syst., 25, 1-22.

Bowers, D. G., and J. H. Simpson (1987), Mean positions of tidal fronts in European Shelf Sea, Cont. Shelf Res., 7, 35-44. 
Brown, J., A. E. Hill, L. Fernand, and K. J. Horsburgh (1999), Observations of a seasonal jet-like circulation at the central North Sea cold pool margin, Estuarine, Coastal Shelf Sci., 48, 343-355.

Brown, J., L. Carrillo, L. Fernand, K. J. Horsburgh, A. E. Hill, E. F. Young, and K. J. Medler (2003), Observations of the physical structure and seasonal jet-like circulation of the Celtic Sea and St. George's Channel of the Irish Sea, Cont. Shelf Res., 23, 533-561.

Chapman, D. C. (2000), Boundary layer control of buoyant coastal currents and the establishment of a shelfbreak front, J. Phys. Oceanogr., 30 , $2941-2955$.

Chapman, D. C., and S. J. Lentz (1994), Trapping of a coastal density front by the bottom boundary-layer, J. Phys. Oceanogr., 24(7), 1464-1479.

Charnock, H., K. R. Dyer, J. M. Huthnance, P. S. Liss, J. H. Simpson, and P. B. Tett (Eds.) (1994), Understanding the North Sea System, 222 pp., Chapman and Hall, New York.

Danielssen, D. S., L. Edler, S. Fonselius, L. Hernroth, M. Ostrowski, E. Svendsen, and L. Talpsepp (1997), Oceanographic variability in the Skagerrak and Northern Kattegat, May-June 1990, ICES J. Mar. Sci., $54,753-773$.

Deleersnijder, E., and P. Luyten (1994), On the practical advantages of the quasi-equilibrium version of the Mellor and Yamada level 2.5 turbulence closure applied to numerical modelling, Appl. Math. Modell., 18, 281-287.

Fernand, L., G. D. Nolan, R. Raine, C. E. Chambers, S. R. Dye, M. White, and J. Brown (2006), The Irish coastal current: A seasonal jet-like circulation, Cont. Shelf Res., 26, 1775-1793.

Garrett, C. J. R., and J. W. Loder (1981), Dynamical aspects of shallow sea fronts, Philos. Trans. R. Soc. Ser. A and Ser. B, 302, 653-681.

Gill, A. E. (1982), Atmosphere-Ocean Dynamics, 662 pp., Elsevier, New York.

Heaps, N. S., and J. E. Jones (1969), Density currents in the Irish Sea, Geophys. J., 51(2), 393-429.

Hill, A. E. (1996), Spin down and the dynamics of dense pool gyres in shallow seas, J. Mar. Res., 54, 471-486.

Hill, A. E., R. Durazo, and D. A. Smeed (1994), Observations of a cyclonic gyre in the western Irish Sea, Cont. Shelf Res., 14(5), 479-490.

Holt, J. T., and I. D. James (2001), An s-coordinate density evolving model of the North West European Continental Shelf: 1. Model description and density structure, J. Geophys. Res., 106(C7), 14,015-14,034.

Holt, J. T., and I. D. James (2006), An assessment of the fine scale-eddies in a high resolution model of the shelf seas west of Great Britain, Ocean Modell., 13, 271-291.

Holt, J. T., I. D. James, and J. E. Jones (2001), An s-coordinate density evolving model of the North West European continental Shelf: 2. Seasona currents and tides, J. Geophys. Res., 106(C7), 14,035-14,053.

Holt, J. T., J. I. Allen, R. Proctor, and F. Gilbert (2005), Error quantification of a high resolution coupled hydrodynamic-ecosystem coastal-ocean model. Part I: Model overview and assessment of the hydrodynamics, J. Mar. Syst., 57, 167-188.

Horsburgh, K. J., A. E. Hill, and J. Brown (1998), A summer jet in the St George's Channel of the Irish Sea, Estuarine Coastal Shelf Sci., 47, 285-294.

Horsburgh, K. J., A. E. Hill, J. Brown, L. Fernand, R. W. Garvine, and M. M. P. Angelico (2000), Seasonal evolution of the cold pool gyre in the western Irish Sea, Prog. Oceanogr., 46, 1-58.

Huthnance, J. M. (1997), North Sea interaction with the North Atlantic Ocean, Deut. Hydro. Zeit., 49, 153-162.

IOC (1985), Manual on sea-level measurement and interpretation, Basic procedures, vol. 1, Intergovernmental oceanographic commission manuals and guides No. 14, 83 pp., IOC, Paris.

James, I. D. (1996), Advection schemes for shelf sea models, J. Mar. Syst., $8,237-254$

Johannessen, J. A., E. Svendsen, S. Sandven, O. M. Johannessen, and K. Lygre (1989), Three-dimensional structure of mesoscale eddies in the Norwegian Coastal Current, J. Phys. Oceanogr., 19, 3-19.
Lenhart, H. J., and T. Pohlmann (1997), The ICES-boxes approach in relation to results of a North Sea circulation model, Tellus, Ser. A and Ser. $B, 49 A, 139-160$.

Luyten, P. J., J. E. Jones, and R. Proctor (2003), A numerical study of longand short-term temperature variability and thermal circulation in the North Sea, J. Phys. Oceanogr., 33(1), 37-56.

Lwiza, K. M. M., D. G. Bowers, and J. H. Simpson (1991), Residual and tidal flow at a tidal mixing front in the North Sea, Cont. Shelf Res., 11, $1379-1395$

Narayanan, C., and R. W. Garvine (2002), Large scale buoyancy driven circulation on the continental shelf, Dyn. Atmos. Oceans, 36, 125-152. OSPAR (2000), Quality Status Report 2000, Region II - Greater North Sea, 136 pp., OSPAR Commission, London.

Pingree, R. D., and D. K. Griffiths (1977), Tidal fronts on the shelf seas around the British Isles, J. Geophys. Res., 3(C9), 4615-4622.

Pingree, R. D., G. T. Mardell, P. M. Holligan, D. K. Griffiths, and J. Smithers (1982), Celtic Sea and Armorican current structure and the vertical distributions of temperature and chlorophyll, Cont. Shelf Res., 1, 99-116.

Prandle, D., G. Ballard, D. Flatt, A. J. Harrison, S. E. Jones, P. J. Knight, S. Loch, J. P. McManus, R. Player, and A. Tappin (1996), Combining modelling and monitoring to determine fluxes of water, dissolved and particulate metals through the Dover Strait, Cont. Shelf Res., 16, $237-257$.

Richardson, K., A. W. Visser, and F. B. Pedersen (2000), Subsurface phytoplankton blooms fuel pelagic production in the North Sea, J. Plankton Res., 22, 1663-1671.

Roed, L. P. (2004), Mean and eddy motion in the Skagerrak/northern North Sea: Insight from a numerical model, Ocean Dyn., 54, 197-200.

Siddorn, J. R., J. I. Allen, J. C. Blackford, F. J. Gilbert, J. T. Holt, M. W. Holt, J. P. Osborne, R. Proctor, and D. K. Mills (2007), Modelling the hydrodynamics and ecosystem of the North-West European continental shelf for operational oceanography, J. Mar. Syst., 65, 417-429.

Simpson, J. H., and D. Bowers (1981), Models of stratification and frontal movement in shelf seas, Deep Sea Res., 28, 727-738.

Simpson, J. H., and J. R. Hunter (1974), Fronts in the Irish Sea, Nature, $250,404-406$

Skogen, M., and H. Soiland (1998), A Users Guide to NORWECOM v2.0 The NORWegian ECOlogical MOLel System, 42 pp., Inst. Mar. Res., Bergen.

Smagorinsky, J. (1963), General circulation experiments with the primitive equations, Mon. Weather Rev., 91, 99-164.

Smith, S. D., and E. G. Banke (1975), Variation of the sea surface drag coefficient with wind speed, $O$. J. R. Meteorol. Soc., 101, 665-673.

Sommerfeld, A. (1949), Partial Differential Equations in Physics, 355 pp., Elsevier, New York.

Song, Y., and D. Haidvogel (1994), A semi-implicit ocean circulation model using a generalized topography-following coordinate system, J. Comput. Phys., 115, 228-244.

Svendsen, E., R. Saetre, and M. Mork (1991), Features of the northern North Sea circulation, Cont. Shelf Res., 11, 493-508.

Turrell, W. R., E. W. Henderson, G. Slesser, R. Payne, and R. D. Adams (1992), Seasonal changes in the circulation of the northern North Sea, Cont. Shelf Res., 12, 257-286.

Winther, N. G., and G. Evensen (2006), A hybrid coordinate ocean model for shelf sea simulation, Ocean Modell., 13, 221-237.

Young, E. F., J. Brown, J. N. Aldridge, K. J. Horsburgh, and L. Fernand (2004), Development and application of a three-dimensional baroclinic model to study the seasonal circulation in the Celtic Sea, Cont. Shelf Res. $24,13-36$

J. Holt and R. Proctor, Proudman Oceanographic Laboratory, 6 Brownlow Street, Liverpool L3 5DA, UK. (jholt@pol.ac.uk) 